\title{
THE DYNAMIC PARAMETERS OF PASSIVE HUMAN AT TEMPORARY DEMOUNTABLE GRANDSTANDS DURING EXPOSURE TO LATERAL VIBRATION
}

\author{
Jian YUAN ${ }^{*}$, Lin HE, Feng FAN, Cong LIU \\ School of Civil Engineering, Harbin Institute of Technology, Harbin, Heilongjiang, China \\ Key Lab of Structures Dynamics Behavior and Control of the Ministry of Education, \\ Harbin Institute of Technology, Harbin, Heilongjiang 150090, China
}

Received 10 January 2018; accepted 22 May 2018

\begin{abstract}
Modelling the interaction between crowds and temporary demountable grandstands with identifying the human dynamic properties are challenges for structure optimal design. In this paper, for investigating and understanding the human and structural lateral dynamic features, a demountable grandstand was tested to obtain its model parameters firstly. Then it is tested at amplitudes between $0.16 \mathrm{~m} / \mathrm{s}^{2}$ to $1.54 \mathrm{~m} / \mathrm{s}^{2}$ with 75 random waves through a shaking table when occupied by twenty persons. Afterword a simplified two-degree of freedom lumped dynamic model of the joint humanstructure system is reinterpreted. Utilizing the state-space model, the passive crowd dynamic parameters are obtained, based on root mean square accumulation error analysis. Statistical analysis of the predictive results concludes that seated crowd model damping ratio is 0.5 , and the probable natural frequency is $2.0 \mathrm{~Hz}$ with the model mass ratio 0.7 . For standing crowd model, the probable natural frequency is $1.5 \mathrm{~Hz}$ with the model mass damping ratio 0.4 , and the model mass ratio is 0.7 . It may have ability to serve as a reference value that can be utilized in vibration safety and serviceability assessment of TDGs, to estimate realistically the vibration response on the occasions when crowd are seated or standing.
\end{abstract}

Keywords: human-structure interaction, temporary demountable grandstand, lateral vibration, experiment, passive crowd dynamic parameters, model analysis.

\section{Introduction}

Temporary demountable grandstands (TDGs) are consisted of hollow bars, with tube-in-tube joints between bays and stories. And the top seating system connected by socket joints with stepped frames and guardrails. The lightweight assembly components of structure with natural frequencies that fall within the frequency range of lively human not only vertical but also horizontal directions. Therefore, structural vibrations triggered by crowds have often been observed during sporting events (Greimann, Klaiber 1978; Tuan, Saul 1985) or rock concerts (Pernica 1983). And even caused spectator discomfort or panic, regrettably leading to several disasters (BBC News 2004; Bolton 1992; Brito, Pimentel 2009), especially 1600 persons were injured and 18 persons died due to crowd activities which led to structure collapse (Bolton 1992). It should go without saying that the prediction of structural dynamic responses and mitigation of excessive structural vibrations, as well as ensuring occupant comfort, are tasks familiar to structural engineers. This has stimulated considerable interest in crowd-structure dynamics and been designated as a design problem to be tackled. Consequently, there are two key areas of human-structure interaction: the human forces induced by crowds have rhythmic actives firstly; secondly, the effects of a crowd on the dynamic properties of occupied structure (Jones et al. 2011; Sachse et al. 2003).

This paper follows with interest the latter key areas issue and just considers passive human only. For predicting the dynamic parameters of passive human, there are many literatures in mechanical engineering (Zhang et al. 2016) and biomechanics (Jalil 2016; Nawayseh 2015). And for civil engineering, published literatures have demonstrated beyond any doubt that human on structures act as dynamic spring-mass-damper systems and the presence of human occupants can change the dynamic behaviour of structures considerably (Sachse et al. 2003). This effect has already

*Corresponding author. E-mail: yuanjian_850809@163.com 
been ongoing from 1987s (Foschi, Gupta 1987) for floor system to 2011s for permanent grandstands (Agu, Kasperski 2011) given a literature review about human-structure dynamic interaction, and a slender structure (Busca et al. 2014) or steel stair (Cappellini et al. 2016). Another research studies regarding the analysis of dynamic response of permanent stadia structures, often subject to widely varying interpretations and many uncertainties were reviewed (Yao et al. 2006) and a flexible test rig was developed for exploring crowd-structure interactions (Harrison et al. 2006, 2008). These results can help for understanding the interaction between human and TDGs. There are also some studies in open literature from the later 1980s that relate directly to temporary grandstands (Crick, Gilbert 2008; Dickie 1983; Dickie, Gibbs 1991; Dickie, Tomlinson 1987; Gibbs 1990; Ji, Ellis 1997; Lasowicz, Jankowski et al. 2015a, 2016a, 2016b; Littler 1996, 2002; Nhleko 2011; Nhleko et al. 2010) for analyzing structural responses. Some other milestone guides (JWG 2008; HSL 2011; IStructE 2007, 2017; LABC 2012; MUTAmarq 2013) that provide recommendations, such as limits on natural frequency or acceleration for TDGs. In addition, a handful of finite element models for TDGs were developed to predict structural properties and responses (Brito, Pimentel 2011; Brito et al. 2014; Jesus et al. 2014; He et al. 2014; Lasowicz, Jankowski 2013; Lasowicz et al. 2015b; Marinho et al. 2006; Yuan et al. 2014). The above literatures focus on structural vertical responses due to vertical loads, while the lateral human-structure interaction is becoming increasing aware of grandstands, which have very low lateral frequencies (Nhleko et al. 2010) and have the lowest stiffness in the transverse direction (Jesus 2014). It needs to investigate the lateral responses of TDGs (Nhleko 2011).

In this paper, for attempting to manifest the dynamic parameters of passive human on TDG which under lateral vibration, a series of experiments were taken of a prototype TDG with twenty persons which was oscillated by an earthquake shake table. Due to the lateral vibrations of TDGs usually derive from human activities, and these excitations have stochastic characters embody in vibration amplitudes which varied with time, so in order to simulate these excitations the stochastic waves just as seismic waves that its amplitudes between $0.56 \mathrm{~m} / \mathrm{s}^{2}$ to $1.54 \mathrm{~m} / \mathrm{s}^{2}$ are chosen. Before this, an efficient and simple description of the equivalent mass-spring-damper system of single degree of freedom (SDOF) for the passive crowd, incorporating a SDOF "structure" modeled as a mass-spring-damper system are assumed for the passive human-structure interaction model. In order to verify the reasonableness of the "structure" model, the empty rig was tested to obtain structural parameters. It is found that structural of the upper that directly contact with crowd (seating system) can be presumed as SDOF for "structure" model, and the structural dynamic parameters are used in this interaction model.

The research objective of this paper is to investigate reasonable dynamic parameters of passive crowd on TDGs. Firstly, based on a feasible range of human dynamic parameters; a mathematical approach state-space model is applied to compute the interaction model. Secondly, the simulated structural acceleration of the interaction model for each crowd parameter set is obtained, and be compared with the experimental results. Finally, the optimization target that the minimum root mean square accumulation error value between simulated and tested results was calculated, to affirm an available crowd parameters combinations. The next section presents the modeling framework and parameters combinations of passive crowd-TDG interaction adopted in this study. In Section 2, through lateral vibration experiments, structural and human dynamic parameters are analyzed based on simulated and tested structural responses. Afterword main findings and discussion are outlined in Section 3. The conclusions will be presented in the final chapter.

\section{Description of the passive crowd-TDG interaction modeling framework}

Human-structure interaction is the name given to the phenomenon which results in the merging of human and structural dynamic properties and the development of new properties for the combined dynamic system (Ji et al. 2003). The presence of passive occupants is known to contribute to a significant amount of damping to the structure system (Ellis, Ji 1997; Lenzen 1996; Pernica 1983; Polensek 1975; Rainer, Pernica 1981). The current state of the art approaches have demonstrated clearly that modelling human merging with one or two mass-spring-damper systems is simple to implement and analyze (Ibrahim 2006; Reynolds et al. 2004; Sachse et al. 2002; Sim 2006; Sim et al. 2006). The properties of the human body found in biomechanics literature may be available for structural engineering applications. It is important to note that, a wide array of values for vertical parameter model representations of passive humans were reviewed (Agu, Kasperski 2011), including the dynamic characteristics of sitting (Wei, Griffin 1998) and standing (Matsumoto, Griffin 2003). Few scientific papers have been published which address the biodynamic properties of the human body when exposed to whole-body vibration (WBV) (Fairley, Griffin 1990; Holmlund, Lundstrom 1998; Mansfield, Lundstrom 1999; Matsumoto, Griffin 2003, 2011; Wei, Griffin 1998), most of them focused on single human at vertical vibration on experimental apparatus (e.g. moving platform). The horizontal dynamic properties of passive crowd on TDGs indepth studies will be analyzed in this paper.

The flow chart in Figure 1 outlines the suggested modeling framework. It shows two different physical sub-systems, i.e. passive crowd and structure. Passive crowd is mathematically assumed as a mass-spring-damper SDOF system or two-degree of freedom (TDOF) (Sim 2006; Sim et al. 2006). For walking human, Venuti et al. (2016) assumed each pedestrian as a SDOF. The single human body mainly contributes only SDOF to the human-structure coupled system is verified by a shaking table (Han et al. 2017). Similarly, for passive crowd will also be assumed 


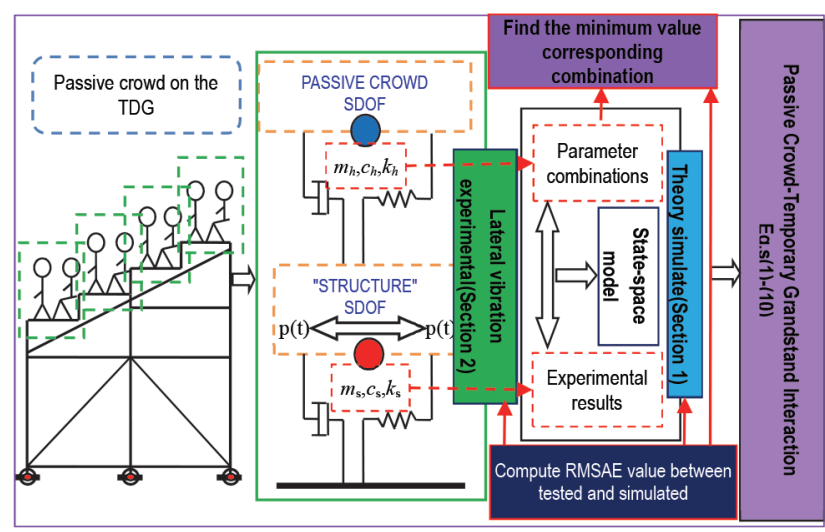

Figure 1. The flow chart of modeling framework

as a SDOF in this paper. The "structure" system is modeled as a mass-spring-damper SDOF system, which refers to structural components directly contacting with human, i.e. seating system. So the TDOF coupled model of passive crowd-structure interaction system is developed through the lateral oscillation. Based on experiment data, the dynamic parameters of crowd are determined by using the root mean square accumulation error (RMSAE) method. The detail of this modeling framework will be presented in the following sections.

\subsection{Dynamic parameters of passive crowd and structure}

For passive human dynamic parameters, a number of published literatures given some feasible values, and some of them were cited in civil engineering. These reference values are presented in Table 1.
Bearing all this in mind, upon further analysis, the most likely range of dynamic parameters of crowd model are considered in this paper as follows: the passive crowd natural frequency $f_{h}$ varies between $0.5 \mathrm{~Hz}$ to $4.0 \mathrm{~Hz}$, damping ratio $\zeta_{h}$ from 0.3 to 0.5 . In this paper, the crowd model mass $m_{h}$ equals to the mass ratio $\gamma$ multiply the crowd weight, and assume $\gamma$ among 0.7 to 1.0. Based on the range of these values, the combination values will be analyzed in Section 3.

For "structure" model, its dynamic parameters are obtained by experimental results. The test structure and measurement points will be described in Section 2. In order to get empty structural model parameters; a rope was tied at the top of structural guardrail and pull it when rope tightened, then suddenly releasing it. So the filtered free decaying vibration curves can be obtained, and shown in Figure 2. There have two free decaying tests, the left figure shown four curves which stand for four test points at each rows (see Figure 7), and the middle figure is the part of their average curve (time from $8 \mathrm{~s}$ to end). The right figure shows the corresponding frequency domain analysis, it revealing there is only a significant dominant frequency, neglecting several tiny peak frequencies at the tail of the curve. So the frequency $2.499 \mathrm{~Hz}$ is assumed as structural damped natural frequency $f_{s}$. According to these free decaying curves, the structural damping ratio is computed by Eqn (1):

$$
\zeta_{s}=\frac{1}{2 \pi j} \ln \frac{\ddot{x}_{i}}{\ddot{x}_{i+j}},
$$

where, $\ddot{x}_{i}$ is the $i$ th acceleration, $\ddot{x}_{i+j}$ is the $(i+j)$ th acceleration. So there are four damping ratio values $6.9 \%, 7.1 \%$,
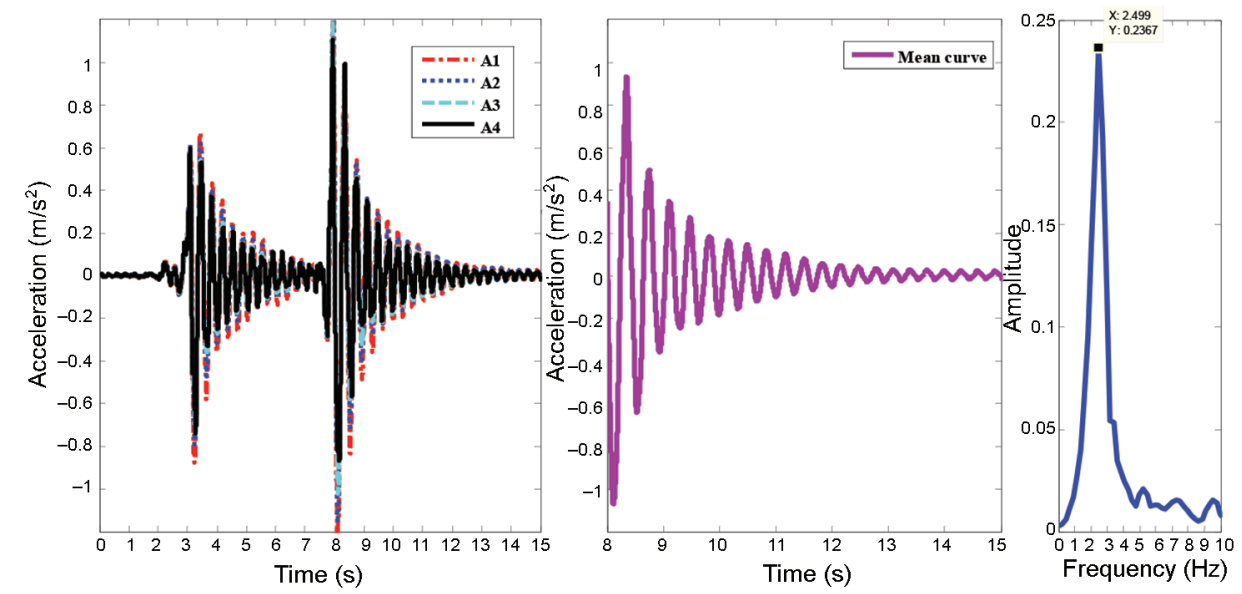

Figure 2. The measured points of time history and frequency domain analysis from free decaying vibration (empty structure)

Table 1. SDOF of passive human (standing and/or sitting dynamic properties are outlined from published literatures

\begin{tabular}{|lccc|}
\hline \multicolumn{1}{|c}{ Vibration direction } & $\begin{array}{c}\text { Natural frequency } \\
(\mathrm{Hz})\end{array}$ & $\begin{array}{c}\text { Damping ratio } \\
(\%)\end{array}$ & Body model mass/Body weight \\
\hline Horizontal vibration (Griffin 1990) & $1-3$ & $30-50$ & $/$ \\
Lateral vibration (Farirley, Griffin 1990) & 1.5 & $/$ & $/$ \\
Lateral vibration (Holmlund, Lundstrom 1998) & $2-4$ & $/$ & 0.77 \\
\hline
\end{tabular}


$7.5 \%$ and $7.6 \%$ respectively. Although there are slight variations of these values, the mean damper ratio $\zeta_{s}$ is given $7.3 \%$ as the model damping ratio.

Then the structural model dynamic parameters $m_{s}, k_{s}, c_{s}$ can be expressed by Eqns (2)-(4):

$$
\begin{aligned}
& f_{s}=f_{u s} \sqrt{1-\zeta_{s}^{2}} ; \\
& k_{s}=w_{s}^{2} m_{s}=\left(2 \pi f_{u s}\right)^{2} m_{s} ; \\
& c_{s}=2 \zeta_{s} \sqrt{k_{s} m_{s}} .
\end{aligned}
$$

Here, structural model stiffness $k_{s}$ and model damping $c_{s}$ can be given by Eqn (3) and Eqn (4) respectively, $f_{u s}$ is the structural undamped natural frequency. In order to get the unknown model mass $m_{s}$, a $78 \mathrm{~kg}$ mass is put on the middle row seat of the test structure and also finished free decaying vibration test, the time history and frequency domain analysis of free decaying curve is shown in Figure 3. It depicts a clearly defined fundamental mode and the damped natural frequency $f_{s}^{\prime}$ is $1.999 \mathrm{~Hz}$. According the decaying curve of the Figure 3, the damper ratio $\zeta_{s}^{\prime} 7.2 \%$ is calculated by Eqn (1). Considering the occupied structure as SDOF, the structural undamped natural frequency $f_{u s}^{\prime}$ is computed by Eqn (5), the damped natural frequency is obtained by Eqn (6). According to Eqn (2), Eqn (3), Eqn (5) and Eqn (6), the structural model mass $m_{s}$ can be deduced in Eqn (7), and the $m_{b}$ equals to the add mass $78 \mathrm{~kg}$, and then the known-parameters will be put into this Equation. So the "structure" model $m_{s}=138.6 \mathrm{~kg}, k_{s}=34164 \mathrm{~N} / \mathrm{m}$, and $c_{s}=318 \mathrm{~N} \cdot \mathrm{s} / \mathrm{m}$ for each row are obtained.

$$
\begin{aligned}
& f_{u s}^{\prime}=\frac{1}{2 \pi} \sqrt{\frac{k_{s}}{m_{s}+m_{b}}} ; \\
& f_{s}^{\prime}=f_{u s}^{\prime} \sqrt{1-\zeta_{s}^{\prime 2}} ; \\
& m_{s}=\frac{f_{s}^{\prime 2} m_{b}}{\frac{f_{s}^{2}\left(1-\zeta_{s}^{\prime 2}\right)}{1-\zeta_{s}^{2}}-f_{s}^{\prime 2}} .
\end{aligned}
$$
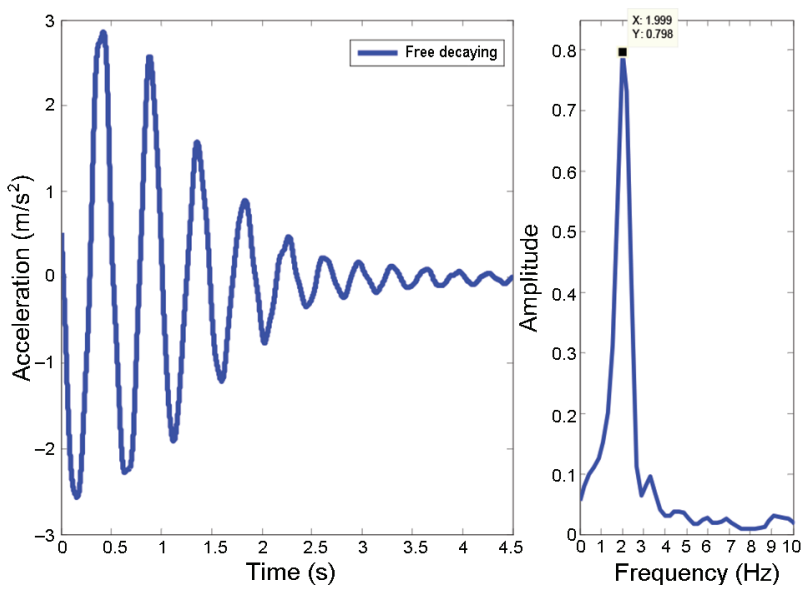

Figure 3. The time history and frequency domain analysis of free decaying curve when test structure was occupied by a $78 \mathrm{~kg}$ mass

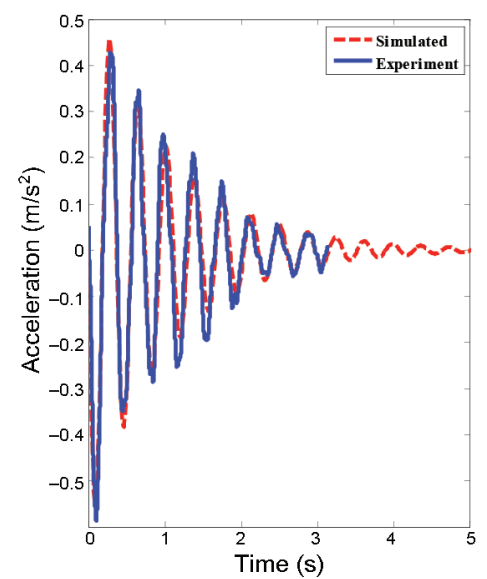

Figure 4. The "structure" model simulated compares with experimental free decaying curve

In order to verify the rationality of the structural model parameters, with $x(0)=35 \mathrm{~mm}$, the simulated acceleration of the structural free decaying curve is identified and compared to the experimental data is shown in Figure 4. From this comparison, the simulated decays are consistent with the measured. Given this, it is reasonable to assume that the SDOF of each row of seating system is appropriate.

\subsection{Modelling human-structure interaction and optimizing crowd parameters}

The passive crowd-temporary grandstand interaction (PCTGI) is described by a dynamic system that couples a SDOF representing a structural vibration mode with adjoining a SDOF representing passive crowd (Figure 1). In the modal domain, the basic equation for ground input is Eqn (8a), due to the "structure" model is considered the seating system (the top of structure) in this paper, so the model force is not equal to the ground force, and the dynamic of the coupled system can be rewritten in a $2 \times 2$ matrix form as Eqn (8b):

$$
\begin{aligned}
& {[M]\{\ddot{x}(t)\}+[C]\{\dot{x}(t)\}+[K]\{x(t)\}=-[M]\{1\} \ddot{x}_{g} ;} \\
& {[M]_{2 \times 2}\{\ddot{x}(t)\}_{2 \times 1}+[C]_{2 \times 2}\{\dot{x}(t)\}_{2 \times 1}+[K]_{2 \times 2}\{x(t)\}_{2 \times 1}=} \\
& \{F(t)\}_{2 \times 1},
\end{aligned}
$$

where the mass $M$, damping $C$ and stiffness $K$ matrices are:

$$
\begin{aligned}
& {[M]=\left[\begin{array}{cc}
m_{s} & 0 \\
0 & m_{h}
\end{array}\right]_{2 \times 2} ;[C]=\left[\begin{array}{cc}
c_{s}+c_{h} \Phi^{2}(x) & -c_{h} \Phi(x) \\
-c_{h} \Phi(x) & c_{h}
\end{array}\right]_{2 \times 2} ;} \\
& {[K]=\left[\begin{array}{cc}
k_{s}+k_{h} \Phi^{2}(x) & -k_{h} \Phi(x) \\
-k_{h} \Phi(x) & k_{h}
\end{array}\right]_{2 \times 2} .}
\end{aligned}
$$

The displacement and force vectors are:

$$
\{x\}=\left\{\begin{array}{l}
x_{s} \\
x_{h}
\end{array}\right\}_{2 \times 1},\{F(t)\}=\left[\begin{array}{c}
p(t) \Phi(x) \\
0
\end{array}\right]_{2 \times 1},
$$




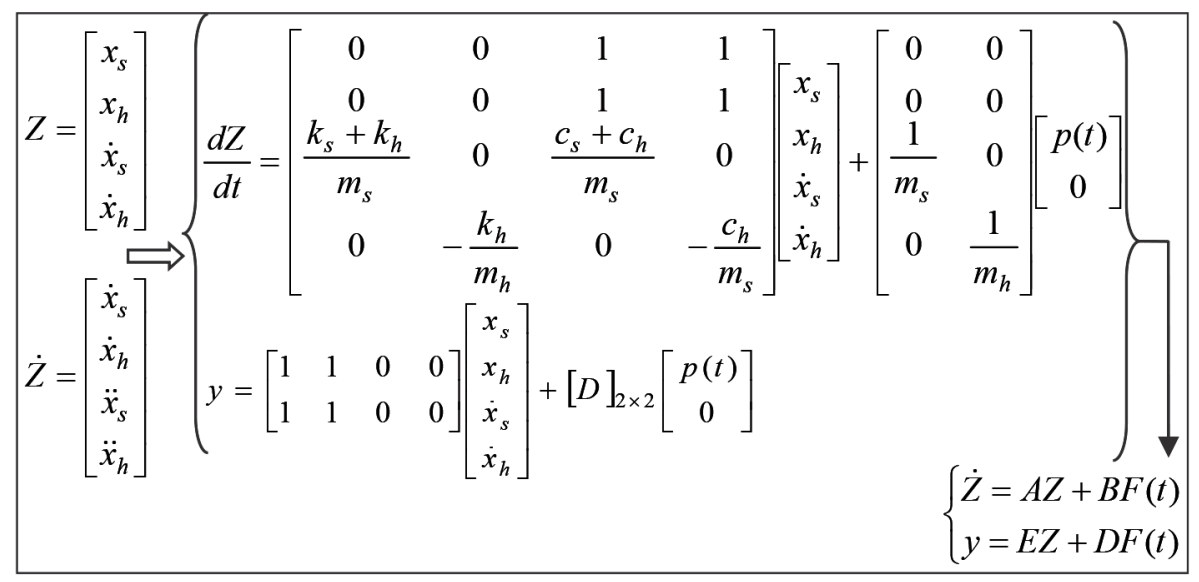

Figure 5. State space model for passive crowd-TDG of 2DOF system

where $m_{s}, c_{s}, k_{s}$ is the model mass, damping and stiffness of "structure" respectively. And $m_{h}, c_{h}, k_{h}$ is the model mass, damping and stiffness of passive crowd respectively. $x_{s}, x_{h}$ is the displacement response of the "structure" and passive crowd model at the lateral oscillation respectively. $p(t)$ as the decoupled lateral force which was derived from the shaking table and will be given in Section 3. While $\Phi(x)$ is the unity-normalized mode shape of "structure". Due to the "structure" and passive crowd has translational motion as a whole. Based on some experimental results (see Figure 15), then simply assumed $\Phi(x)=1$ in this paper.

Conventionally, Eqn (8) is rewritten into the following by an analytical method that is a discrete time state-space model (Figure 5). $A$ is the transition state matrix describing the dynamic of the system, $B$ is the input matrix, $E$ is the output matrix and $D$ is the direct transmission matrix. The Simulink module of mathematical software MATLAB (The MATHWORKS 2010) is utilized to compute this system.
The potential ranges of passive crowd dynamic parameters have been given in Section 2.1. Upon further analysis the optimization parameters are found to be, there are $432(36 \times 3 \times 4)$ parameter combinations, i.e. the array of passive crowd natural frequency $f_{h}$ is set in 0.1 step increasing from $0.5 \mathrm{~Hz}$ to $4.0 \mathrm{~Hz}$ (thirty six frequencies), the damping ratio $\zeta_{h}$ is set in 0.1 step increasing from 0.3 to 0.5 (three damping ratios), and the mass ratio $\gamma$ is set in 0.1 step increasing 0.7 to 1.0 (four mass ratios). The flow chart in Figure 6 elaborates the complete process (algorithm) of obtaining optimization dynamic parameters of crowd. The algorithm creates the model mass, stiffness and damping matrix of 2DOF coupled system with 432 of $m_{h}, k_{h}, c_{h}$ combinations firstly. Then from the each dynamic properties matrix cluster, corresponding to a set of multiple state-space model parameters, $A, B, E$ and $D$ are computed respectively. Thirdly, the $p(t)$ as input excitations of this state-space model, which are derived from 75 experimental records obtained from the shaking table, and

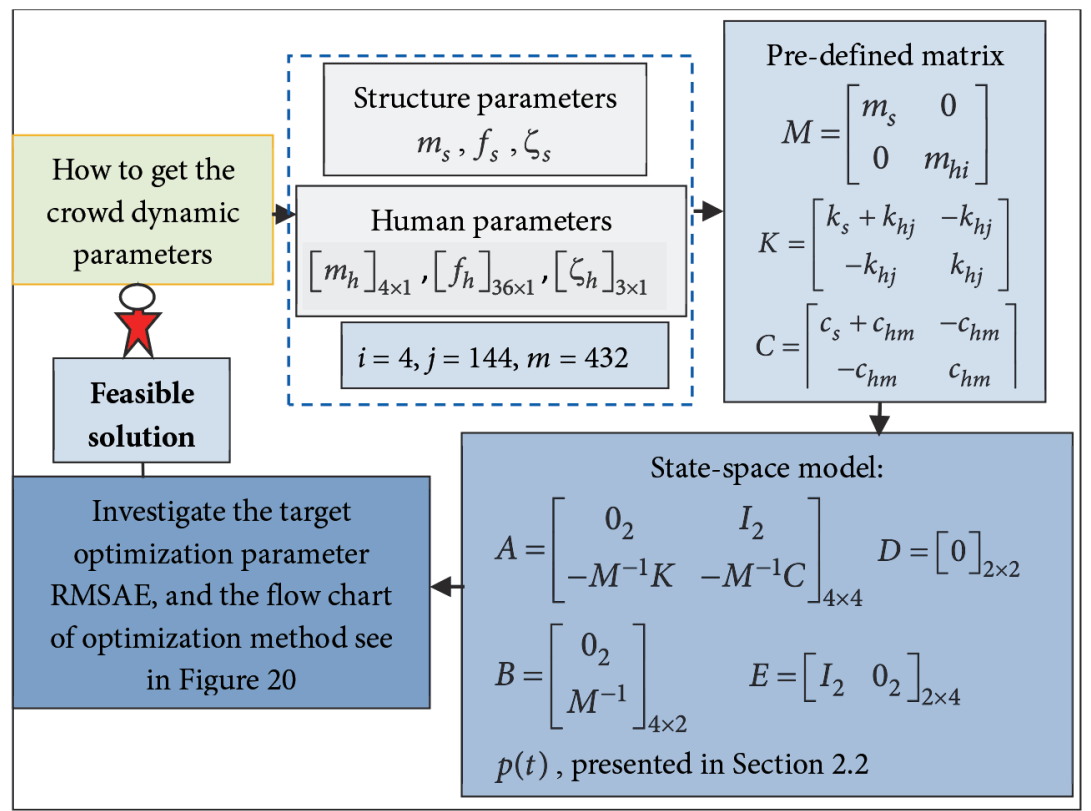

Figure 6. Algorithm describing the procedure for obtaining available human dynamic parameters 
more details will be presented in Section 2. Finally, simulated response of "structure" for each input excitation was obtained, and the root mean square accumulation error (RMSAE) value that calculated by Eqn (11) as optimal target value for seeking feasible dynamic parameters of passive crowd. All the algorithms are achieved by programming with MATLAB, and detailed results are discussed in the next Section.

The root mean square accumulation error (RMSAE) is computed by Eqn (11):

$$
\text { RMSAE }=\sqrt{\frac{\sum_{i}^{N}\left(a_{t, i}-a_{s, i}\right)^{2}}{N}},
$$

where $a_{t, i}$ is the $i$ th data of experimental acceleration curve; $a_{s, i}$ is the $i$ th data of simulated acceleration curve; $N$ is the number data of experimental or simulated curve.

\section{Experiment and results of optimization}

To better understand the passive human-TDG's interaction vibration which oscillated via horizontal excitation, a temporary demountable grandstand rig was constructed and vibrated on a shaking table at the Key Lab of Structures, Dynamic Behavior and Control of the Ministry of Education at the Harbin Institute of Technology. According to the experimental results with aforementioned algorithm, and the passive crowd dynamic parameters are investigated. These will be presented in the next three sections respectively.

\subsection{Experiment arrangement}

Table 2 depicts the test TDG members, its weight and structural schematic. The structure is comprised of nine kinds of members, which shown in schematic. There are four rows and five columns seats that accommodating 20 persons. Seating system includes guardrails, seat braces, seat beams and decks and stepped frames. Hollow bar of supporting system includes standards, ledgers, bay bracings and base jacks. The type of connection employed to assembly the hollow bars is plug-pin joint, which shows in Table 2, and the deck laps on the seat braces and triangular stepped frame. The weight of empty structure is $912.98 \mathrm{~kg}$.

In Figure 7, the main dimensions of a structure are: height of front row $(2.6 \mathrm{~m})$, back $(4.0 \mathrm{~m})$, left-to-right span $(2.5 \mathrm{~m}$ ) and front-to-back span (up to 3,0 m). Four accelerometer points A1-A4 stands for the accelerations of each rows, and A0 stands for shaking table's acceleration. Also there are three linear variable differential transformers (L1-L3) are shown in this figure. The accelerator point A1-A4 measured the responses of structural seating system is presumed as the responses of the "structure" of crowd-TDG coupled model. Data were collected at a sampling frequency of $1 \mathrm{kHz}$ using IMC data acquisition software carrying a built-in anti-alias filter (German model IMC CRONOS compact-400-08 with robust housing) and a DH5922 (Dong Hua, China). The recorded curves were digitally filtered with a frequency content of up to $25 \mathrm{~Hz}$ in order to minimize the effect of background noise. Finally, the adjustable bearing of the test rig had to be sufficiently robust with a bolted connection in the shaking table to prevent sliding due to the impact of seismic waves resulting from side-to-side motions.

Three kinds of seismic waves: Chi Chi (1999s), El Centro (1940s) and Kobe waves (1995s), including two lateral directions, West-East (W-E) and North-South (N-S) were chosen as horizontal force to the test rig. The peak acceleration of these random waves between $0.16 \mathrm{~m} / \mathrm{s}^{2}$ to $1.54 \mathrm{~m} / \mathrm{s}^{2}$ with 53 force testing sessions in total (see Table 3). For example, there are nine test curves of Chi Chi (W-E) from the peak acceleration 18.29 gal to $91.45 \mathrm{gal}$ increasing 0.5 times, i.e.: 18.29 gal, 27.43 gal $(18.29 \times 1.5)$, 36.58 gal $(18.29 \times 2)$, 45.73 gal $(18.29 \times 2.5), 54.87$ gal (18.29×3), 64.02 gal $(18.29 \times 3.5), 73.16$ gal $(18.29 \times 4)$,

Table 2. Test structure

\begin{tabular}{|c|c|c|c|c|}
\hline TDG & Kinds of member & Mass (kg) & Schematic of structure & Plug-pin joint \\
\hline \multirow{4}{*}{ Seating system } & $\begin{array}{l}\text { (1) Guardrail } \\
\text { (include Poles) }\end{array}$ & 234.80 & & \\
\hline & (2) Seat brace & 80.46 & & \\
\hline & (3) Seat beam & 114.45 & & \\
\hline & (4) Deck & 120.00 & & \\
\hline \multirow{7}{*}{$\begin{array}{l}\text { Hollow bar } \\
\text { of supporting } \\
\text { system }\end{array}$} & $\begin{array}{l}\text { (5) Triangular } \\
\text { stepped frame }\end{array}$ & 92.80 & & \\
\hline & (6) Standard & 66.68 & & \\
\hline & (7) Ledger & 113.75 & & \\
\hline & (8) Bay bracing & 69.04 & & \\
\hline & (9) Base jack & 21.00 & & \\
\hline & (10)Vibration table & I & & \\
\hline & Total & 912.98 & & \\
\hline
\end{tabular}




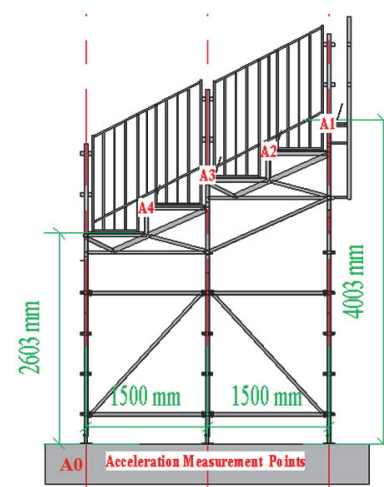

(a) Right side view

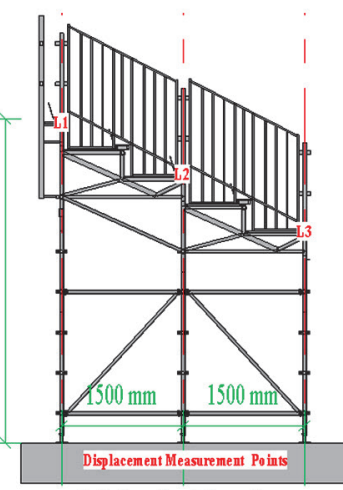

(b) Left side view

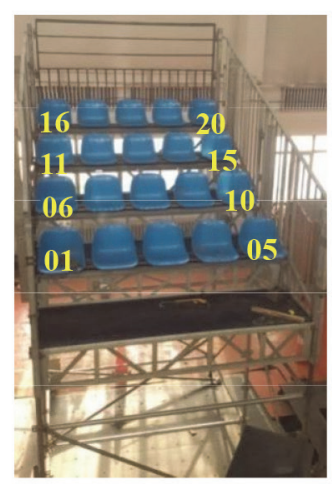

(c) Elevation view

Figure 7. Overall geometry of grandstand rig

82.31 gal $(18.29 \times 4.5), 91.45$ gal $(18.29 \times 5.5)$, other kinds of test curves are the same increasing method. The shaking table was controlled by displacement curve, one of them are showing in Figure 8.

The twenty participants (Figure 9(a)) consisted of volunteers from the university and society, and test subjects were allowed to take a helmet and occupy the test rig with seatbelts. The red number stands for participant's seat number, and the black number stands for participant's body weight. Before carrying out the lateral vibration tests when the structure was occupied by the crowd, twenty sandbags (each sandbag $70 \mathrm{~kg}$, or $1400 \mathrm{~kg}$ total)
Table 3. Details of test seismic waves

\begin{tabular}{|lcccl|}
\hline \multicolumn{2}{|c}{ Seismic wave } & $\begin{array}{c}\text { Peak acceleration } \\
(\mathrm{gal})\end{array}$ & $\begin{array}{c}\text { Duration } \\
(\mathrm{s})\end{array}$ & Number \\
\hline $\begin{array}{l}\text { Chi Chi } \\
\text { (1999s) }\end{array}$ & W-E & $18.29-91.45$ & 48 & 9 \\
El Centro & N-S & $16.26-89.43$ & 46 & 10 \\
\cline { 2 - 5 }$(1940 s)$ & N-S & $21.48-96.66$ & 40 & 8 \\
Kobe & W-E & $30.78-153.90$ & 30 & 9 \\
$(1995 s)$ & N-S & $30.57-152.85$ & 40 & 9 \\
\hline
\end{tabular}

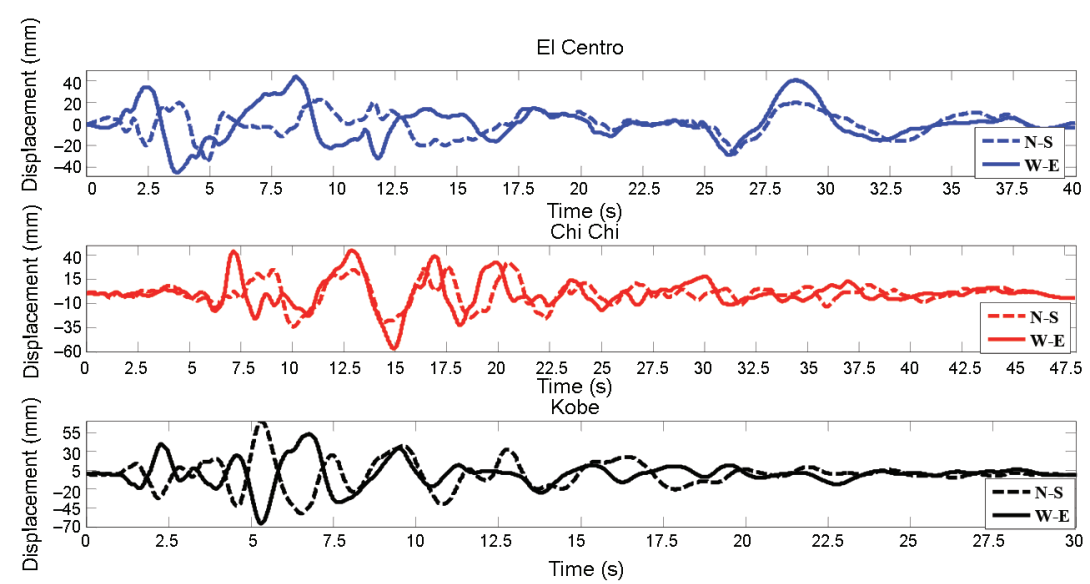

Figure 8 . The shaking table under displacement-controlled loading

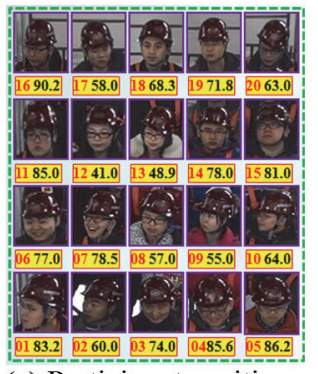

(a) Participant position number and weight
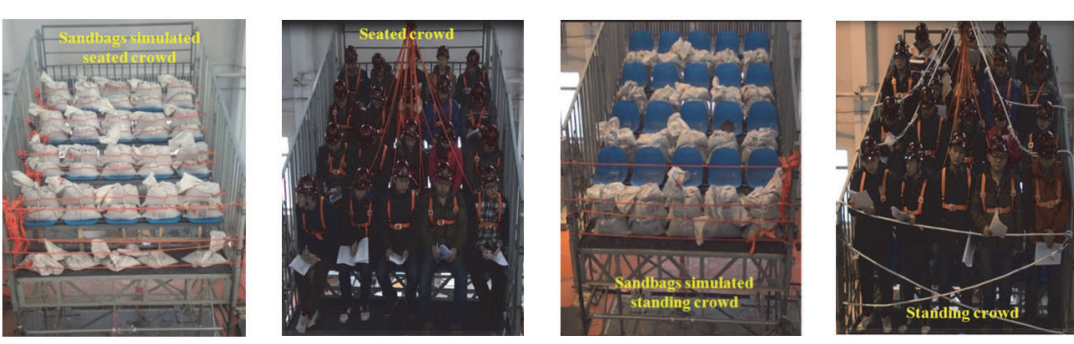

(b) Structure occupied by sandbags and crowd

Figure 9. Participant and test structure conditions 


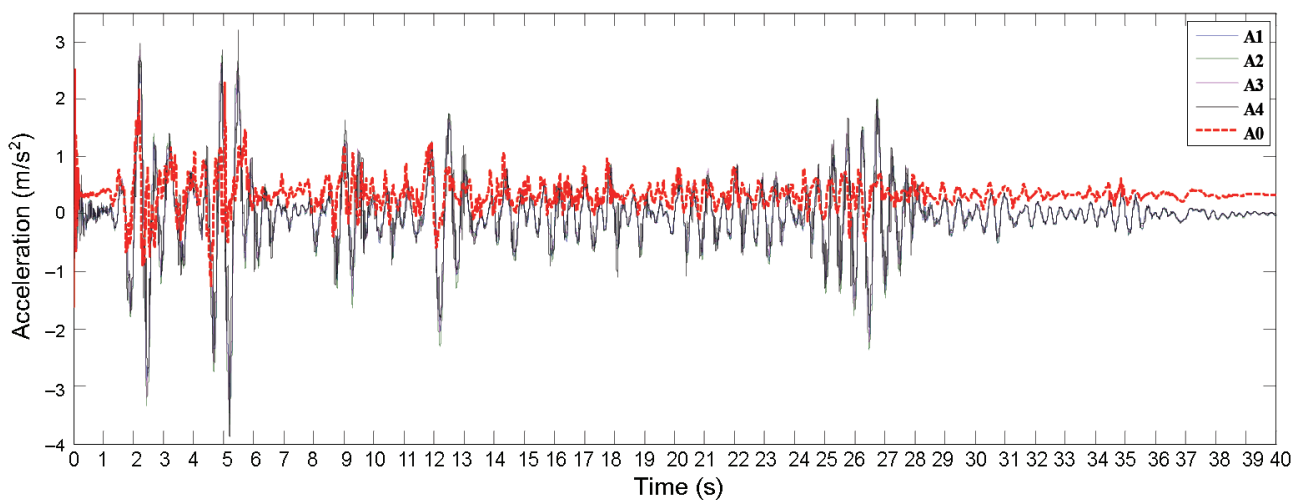

Figure 10. The acceleration curves of A1-A4 and input acceleration A0 when structure is empty

were tested in order to cheek the safety of structure. The total weight of twenty participants was $1405.7 \mathrm{~kg}$ that closes to the total weight of the sandbags. The occupied configurations investigated were as follows: structure loaded sandbags simulated person seated; structure was occupied by seated crowd; structure loaded sandbags simulated person standing; structure was occupied by standing crowd. These four test conditions are shown in Figure 9(b). Empty structure and the four occupied configurations structure is oscillated by 53 random waves with shaking table respectively. All tests were preceded by a rigorous risk assessment and approval by the university's research ethics committee. Two first aid officers were present in the laboratory during all test sessions. All of the structural dynamic responses of acceleration were recorded when structure is empty, occupied by sandbag and crowd respectively.

\subsection{Decoupled input excitation of coupled model}

When the test structure was oscillated by the shaking table, the lateral force applied at the structural base jack, with the shaking table back and forth movement set up inertia forces; the structure has dynamic responses. In Figure 10, the measured curve of A1-A4 and the acceleration of the shaking table A0 are shown respectively, when test wave is one of the El Centro (N-S) waves. Based on visual observation of the variations between them, they seem to be analogous to each other. And the structural peak accelerations are significantly greater than shaking table's peak accelerations. So it is unreasonable to use A0 as the input excitation $p(t)$ of the passive crowd-structure interaction model in this paper.

Prior to investigate the shaking table input excitation and "structure" input excitation, the dynamic responses of structure must be correctly processed. For acceleration, there are three common approaches to determining vibration amplitude: peak, root-mean-square (RMS) and vibration dose value (VDV). Due to VDV approach may be more suitable for the structural dynamic curves where distinct peaks occur, different from RMS accelerations depend too heavily on the duration of an event to act as an accurate gauge of response severity (Jones et al. 2011). So, the shaking table's acceleration and structural dynamic re- sponses are quantified in terms of the vibration dose value (VDV), which is calculated in Eqn (12) for both a continuous and digitized signal:

$$
\begin{aligned}
a_{V D V}= & \left\{\int_{0}^{T} a_{w}^{4}(t) d t\right\}^{\frac{1}{4}}=\left(\lim _{\lambda \rightarrow 0} \sum_{i=1}^{n} a_{w}^{4}\left(s_{i}\right) \cdot \Delta t_{i}\right)^{0.25}= \\
& \left(\sum_{i=1}^{n}\left[W\left(f_{s}\right) \cdot a\left(t_{i}\right)\right]^{4} \cdot f\right)^{0.25} ; \\
\lambda=\max \left\{\Delta x_{1}, \Delta x_{2}, \cdots, \Delta x_{n}\right\}, &
\end{aligned}
$$

where $a_{V D V}$ is vibration dose value of acceleration $a(t)$ in $\mathrm{m} / \mathrm{s}^{1.75} ; \varsigma_{i}$ is the integration point that equal to timing point $t_{i} ; a_{w}(t)$ is the frequency weighted acceleration equal to $a(t) \cdot W(f)$, and $W(f)$ is the frequency weight function from ISO $2631(1997,2003) ; f_{s}$ is the empty structure natural frequency, according to the ISO 2631 $(1997,2003)$, the value of 0.74 is used in this paper; $a(t)$ is the digitized sample of the experimental acceleration, it is the mean curve of A1-A4 in this paper; $T$ is the vibration duration in seconds, and $f$ is the sampling frequency, with $n=T / f$ as the number of points in the signal; $\Delta x_{i}$ is the $i$ th integral interval point. In this paper the Eqn (12) is used for calculating the same kind of excitation with different amplitudes to reflect the structural dynamic performance. So it does not occur incorrect due to different set, for example, $\{1,2,3,4,5,6,7,8,9,10\}$ and $\{10,9,8,7$, $6,5,4,3,2,1\}$ are two sets of data, because if it is evaluated using VDV, it will lead to the same answer, however, it is incorrect to think the two sets of data are similar. While in this paper, the order of the elements of $a(t)$ is invariant (just like the Figure 10 shows the shape of curves), only the size of element increases linearly, i.e. $\{1,2,3,4,5,6,7$, $8,9,10\}$ and $\{2,4,6,8,10,12,14,16,18,20\}$ and so on.

Thus, the acceleration VDVs of A1-A4 against VDVs of A0 when the test structure was oscillated by these waves in Table 3 are computed by Eqn (12). Consider the mean value of A1-A4 calculated value as the VDV of "structure", and plotted against the input VDV of A0, which is shown in Figure 11. A linear relationship between VDV of "structure" and VDV of A0 seems to be rather evident in each test conditions, not only the structure empty (blue data), 

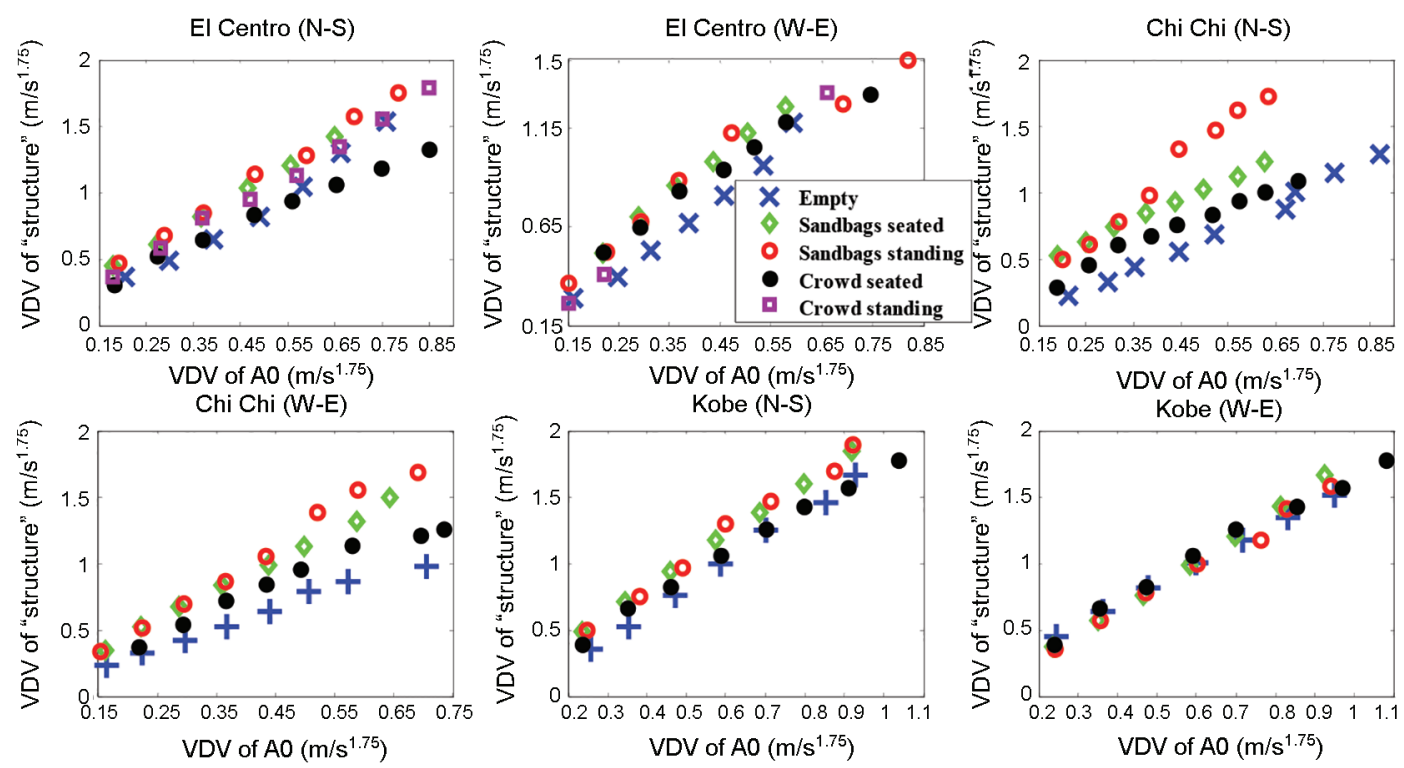

Figure 11. VDV of "structure" against VDV of A0

or occupied by sandbags (green and red data), but also crowd at the structure (black and purple data). So it may be reflected that the dynamic response of structure has linear change with increasing input excitation. In this case, the input force $p(t)$ is assumed in Eqn (13):

$$
p(t)=\beta m a_{0}(t),
$$

where $m$ is the mass, it equals to $m_{s}$ for the empty structure; it equals to $m_{s}+m_{\text {bag }}$ when the structure with sandbags and $m_{b a g}$ stands for the weight of sandbags; it equals to $m_{s}+m_{h}$ when the structure was occupied by crowd, and the crowd model mass $m_{h}=\gamma \cdot \sum_{i}^{k} m_{p i}, k$ is the number person of crowd, $m_{p i}$ is the body weight of $i$ th person; $a_{0}(t)$ is the acceleration of shaking table that recorded by accelerometer of $\mathrm{A} 0$ point. The parameter $\beta$ is presumed as decoupled transfer coefficient, which meaning the input force of the shaking table is converted to the input force of crowd-structure coupled model.

In order to confirm a feasibility value of $\beta$ at each test condition, the analysis error $\Delta=\left|a_{v d v o u t p u t}-a_{v d v o u t p u t}^{\prime}\right| \leq 0.05$ is utilized, where $a_{v d v o u t p u t}$ is the mean value of VDV of A1-A4 when acceleration curves was measured, and $a_{v d v o u t p u t}^{\prime}$ is the VDV of simulated curve of model. For bare structure, the dynamic parameters of "structure" $m_{s}, f_{s}, \zeta_{s}$ are give in Section 1.1, and the "structure" is calculated SDOF; when the test structure was occupied by sandbags, the "structure" is also considered as SDOF model, and the natural frequency is computed in Eqn (14):

$$
f_{b a g}=\sqrt{\frac{1}{1+\frac{m_{b a g}}{m_{s}}}} f_{s},
$$

where $f_{b a g}$ is the natural frequency of "structure" with sandbags; $m_{\text {bag }}$ is the model mass of sandbags, $350 \mathrm{~kg}$ that equal to five sandbags on one row seat is assumed in this paper, and $m_{s}, f_{s}$ has given $2.499 \mathrm{~Hz}, 138.6 \mathrm{~kg}$ in Section 1.1 respectively. Passing the three known values as input parameters of this formula, $f_{\text {bag }}=1.33 \mathrm{~Hz}$ is obtained. And the structural model damping ratio is also supposed as $7.3 \%$.

So, using the structural SDOF model, based on the recorded acceleration of A0 and A1-A4 when structure is empty or occupied by sandbags, the variable parameter $\beta$ will be found a feasible value when the analysis error less than $5 \%$. For example, when the A0 curve was one of the Chi Chi (W-E) waves experiment, the feasible $\beta$ value is 1.21 and 0.97 when structure is empty and occupied by seated sandbags respectively, comparison of the simulated curve with experimental curve in time domain and frequency domain are shown in Figure 12 and Figure 13. By visual inspection of the shapes among them in time domain, it was possible to identify that blue curves (simulated) closely approximated the experimental curve (red dotted lines), and the frequency domain is just like this.

Then the feasible parameter $\beta$ values that corresponding each test condition (empty structure and sandbags at structure) are obtained and shown in Figure 14. In interpreting this figure, it is worth noting that the feasible $\beta$ values are kept within a certain range of variation and have a plateau with an increasing amplitude of input at six kinds of random wave experiments. It suggests that the SDOF of "structure" model is reasonable, not only for the seating system of an empty structure but also an occupied one.

For analyzing the mode shape of "structure", the displacement measured points L1-L3 data are collected. For example, the displacement curves of L1-L3 when the structure was oscillated by one of the El Centro waves are shown in Figure 15. Figures 15a to 15e stand for the structure was empty, it is occupied by sandbags and crowd, respectively. With visual observation of each three curves, 


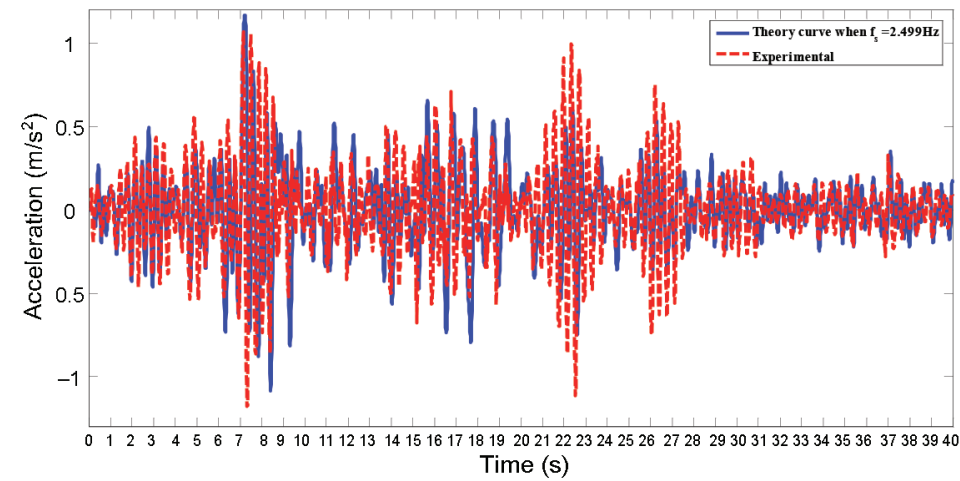

(a) Time history curve

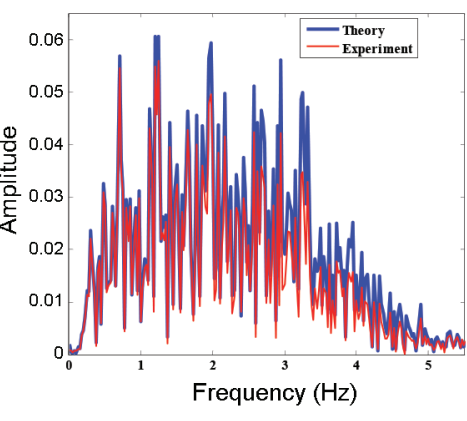

(b) Frequency domain analysis

Figure 12. Comparison in time domain and frequency domain between simulated and experiment when empty structure was oscillated by one of the Chi Chi (W-E) waves and $\beta$ is 1.2

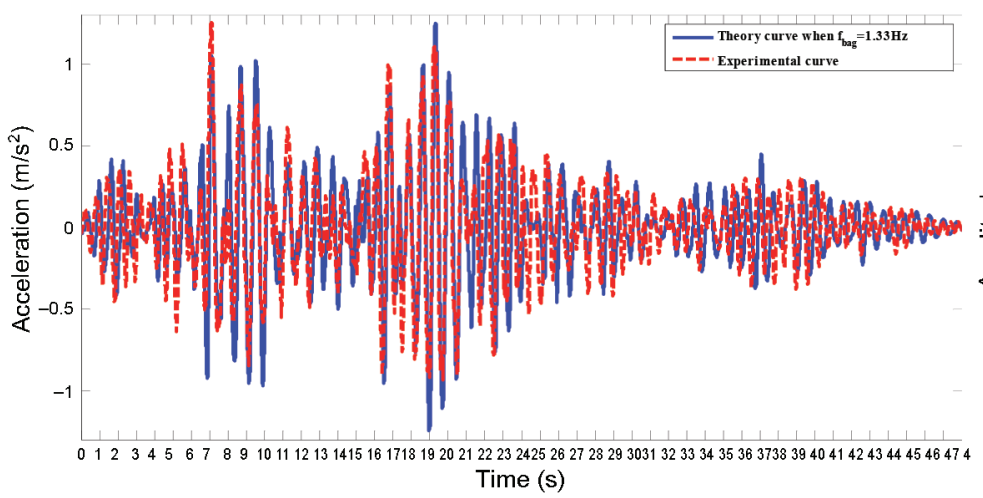

(a) Time history curve

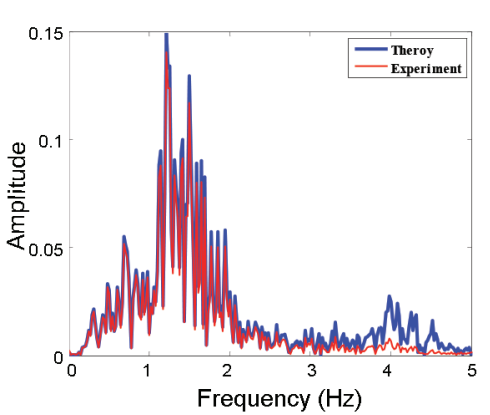

(b) Frequency domain analysis

Figure 13. Comparison in time domain and frequency domain between simulated and experiment when sandbags at structure was oscillated by one of the Chi Chi (W-E) waves and $\beta$ is 0.97

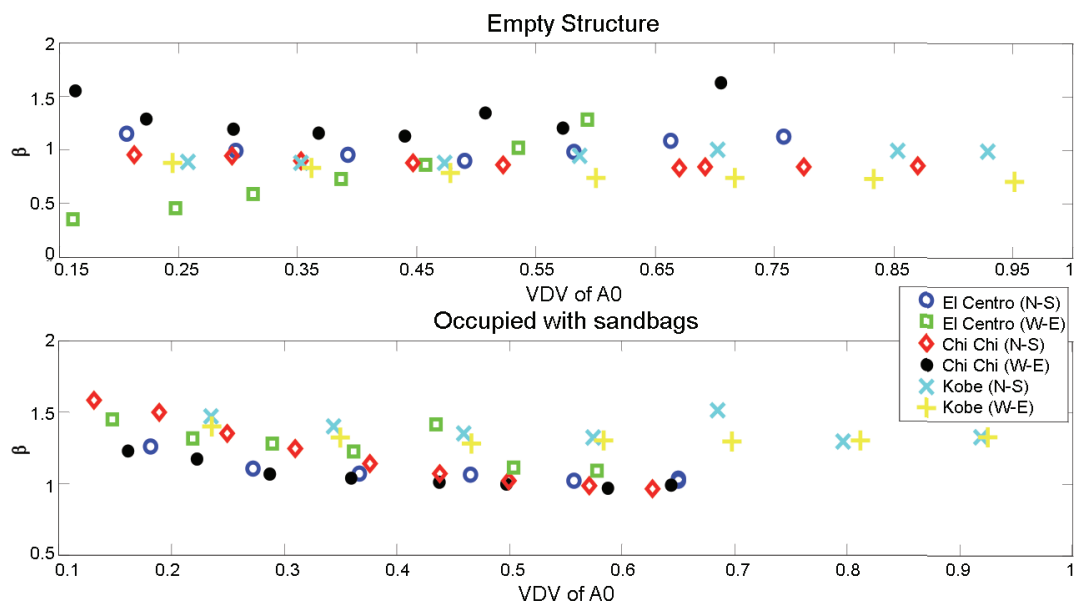

Figure 14. The input VDV of A0 against calculated $\beta$ when structure empty and occupied by seated sandbags 

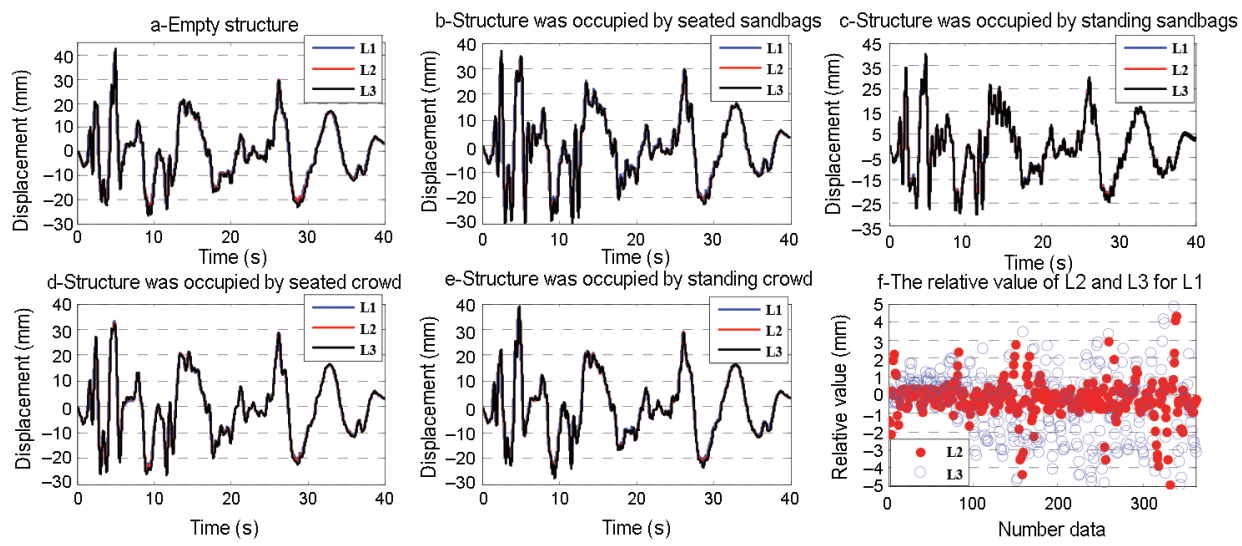

Figure 15. The displacement curves of L1-L3 and the relative values of L2 and L3 for L1

there are quite a bit of overlaps, and the peak values of all the experimental curves of L1-L3 are extracted. Then the relative values of L2 and L3 for L1 are calculated and depicted in Figure 15f, which showing the distribution of these relative values. The max value is not more than $5 \mathrm{~mm}$, it is very small for the distance of $1.5 \mathrm{~m}$ between displacement test points. So it may indicate that the top of structure has a whole translational motion, and without torsion vibration. Bearing all this in mind, it can be assumed $\Phi(x)=1$ in this paper.

\subsection{Dynamic parameters of passive crowd on TDG}

In order to understanding the interaction between structure and crowd, the structural natural frequencies are analyzed when the structure was occupied by sandbags and crowd. Due to the weight of occupied structure is particularly heavy, it is difficult for people pull it with a rope, so the amplitude of 500 gal of white-nose wave was used to oscillate it by the shaking table. And the frequency domain results of $A 1$ showing that there are higher frequencies in Figure 16(a). And the first frequency of the empty structure is about $2.8 \mathrm{~Hz}$, closing to the result $2.5 \mathrm{~Hz}$ which obtained by a rope pulled experiment. When focus on the variation of the first frequency, the peak amplitudes of the red curves are smaller than blue curves, let alone black curve, and what is more, the first frequency of the structure was occupied by crowds (red curves) is about $1.5 \mathrm{~Hz}$, changed more small than the first frequency $2.0 \mathrm{~Hz}$ when the structure was occupied by sandbags (blue curves), both of them implied that the crowd have had a significant damping effect on the structure. Except for that, a sin wave was used to oscillate the structure when it occupied by sandbags, and twenty persons swayed the structure, both of the displacement of L1 were recorded respectively, which are shown in Figure 16(b). The domain analysis of its decaying curve also indicated that the frequency of structure occupied by crowd more smaller than structure occupied by sandbags.

For the lateral vibration experiment using the shaking table when test structure was occupied by twenty persons, seventy five effective accelerations A1-A4, A0 are recorded respectively. Due to the dynamic parameters of crowd model to be studied, according to the investigation of parameters $\beta$ in above, the range of $\beta$ is set from 0.5 to 2.2 in 0.1 step when calculate the crowd-structure interaction model firstly. Then 432 combination parameters $m_{h}, k_{h}, c_{h}$ are given, and the coupled model will be computed by the state-space model (Figure 5). Based on each crowd dynamic combination parameter, and the known structural dynamic parameters at each $A 0$ with a $\beta$ value, 432 structural acceleration curves are simulated. Afterwards, there will be 432 RMSAE values are obtained through Eqn (11), just like the Figure 17 depicts the distribution of RMSAE values when the test wave is one of the Chi Chi (N-S) when $\beta$ equal to 2.2. The two abscissa axes of this $3 \mathrm{D}$ chart is the crowd model mass ratio $\gamma$ and crowd model frequency $f_{h}$ respectively, the vertical coordinate is RMSAE value. And the 144 data of green, blue and red surface stands for the crowd model results when damping ratios $\zeta_{h}$ is $0.3,0.4$ and 0.5 , respectively. As can be seen in this figure, the minimum value of 432 RMASE on the red surface, and it is $0.383 \mathrm{~m} / \mathrm{s}^{2}$, which corresponds the combination crowd dynamic parameters: crowd model frequency $f_{h}$ is $1.7 \mathrm{~Hz}$, crowd model damping ratios $\zeta_{h}$ is 0.5 , and the crowd model mass ratio $\gamma$ is 0.7 . It is fundamental that this is the first step analysis for getting reasonable crowd dynamic parameters.

And secondly, for each experiment the parameter $\beta$ from 0.5 to 2.2 in 0.1 step, eighteen the min RSMAE values can be acquired. For example, eighteen values of each experiment when the excitation is one of the Chi Chi (N-S) waves, and there are ten experimental curves with different amplitudes, so there are one hundred eighty values in total, showing in Figure 18. In this figure, the horizontal axis is parameter $\beta$, the vertical axis stands for the min RMSAE value, each curve consists of eighteen data, and the different values of the input VDV in this chart stand for ten different amplitudes oscillation experiment. It is noticeable that every curve of the variation of the min RSMAE values with variate $\beta$ undergoes a process of falling firstly then stepping upwards later. 


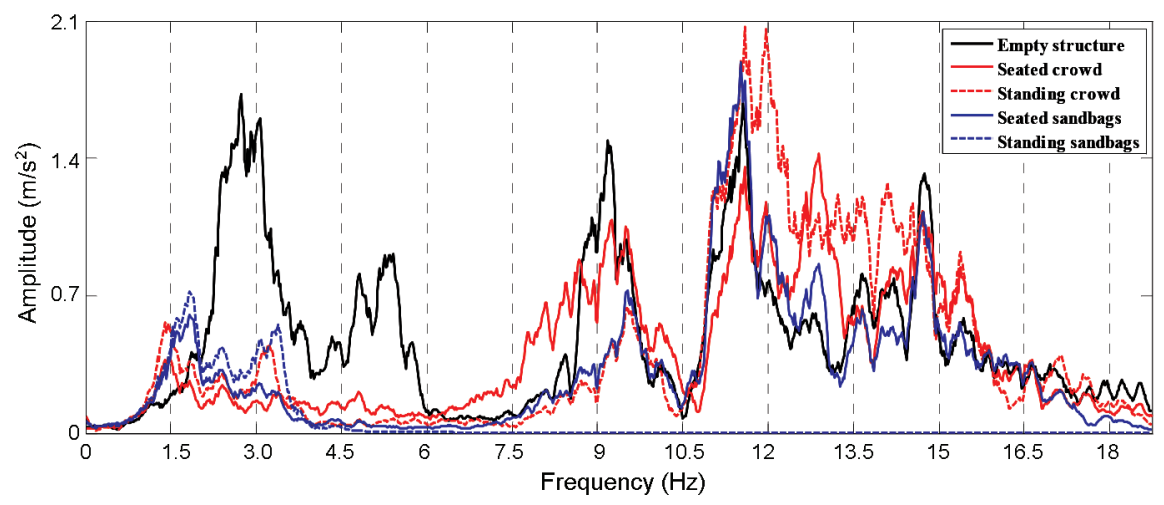

(a) A white-nose wave oscillation experiment
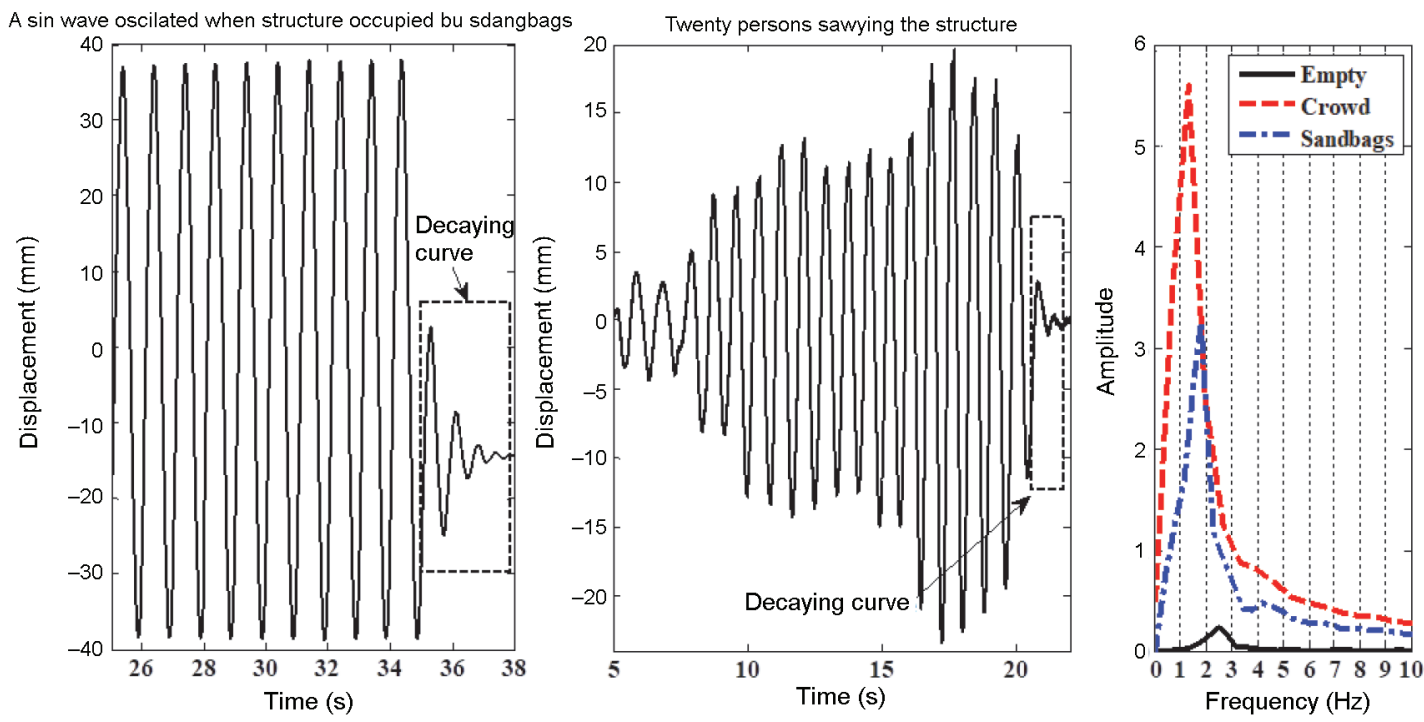

(b) Sin wave oscillation and crowd swaying results

Figure 16. The structural frequencies when it occupied by sandbags or crowd or empty

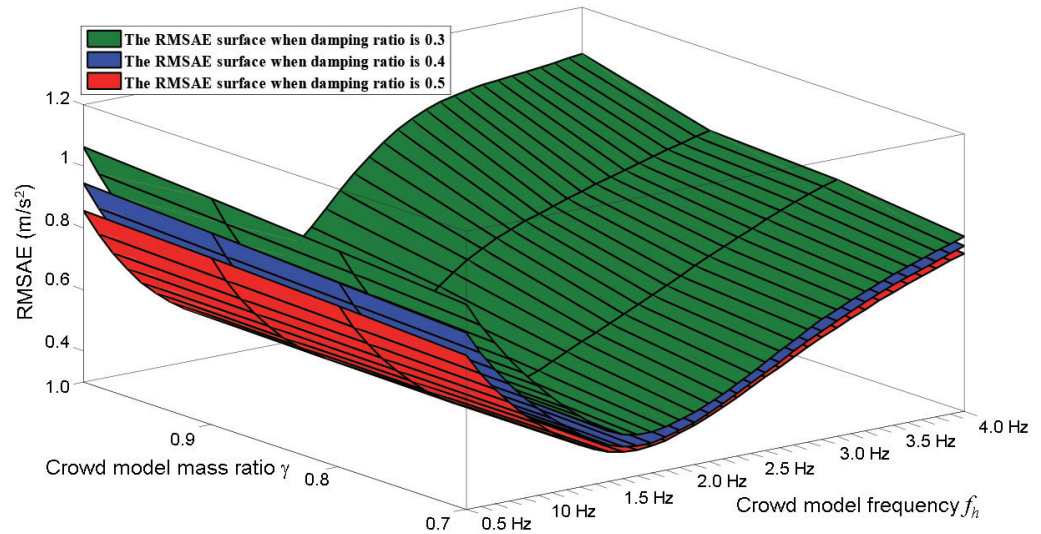

Figure 17. The distribution of RSMAE resulting from a Chi Chi (N-S) seismic wave, when $\beta=2.2$ excitation 


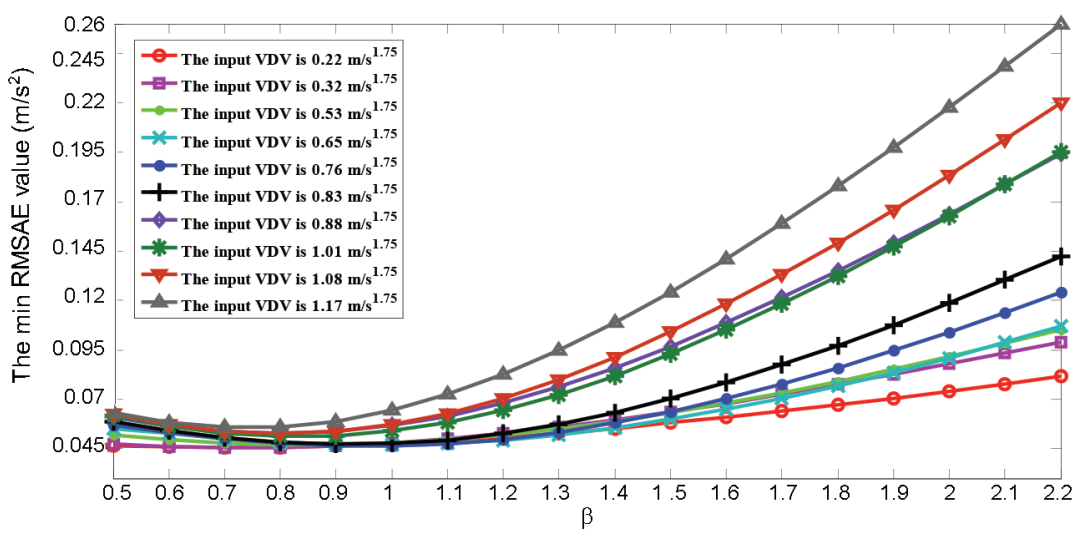

Figure 18. The minimum RSMAE values against eighteen $\beta$ with ten different amplitudes of Chi Chi (N-S) seismic wave

Meanwhile, each min RMSAE value corresponds a crowd model dynamic parameters combination will be collated. Figure 18 shows these min RMSAEs which corresponding crowd model frequencies $f_{h}$ are given in Figure 19. It displays these obtained frequencies with increasing parameter $\beta$ and the amplitude of inputs. From the distribution of these frequencies, the first three experiments that the input VDV is $0.22 \mathrm{~m} / \mathrm{s}^{1.75}, 0.32 \mathrm{~m} / \mathrm{s}^{1.75}$ and $0.53 \mathrm{~m} / \mathrm{s}^{1.75}$, the crowd model frequency value is higher with increasing $\beta$, i.e. from $1.3 \mathrm{~Hz}$ to $1.7 \mathrm{~Hz}, 1.4 \mathrm{~Hz}$ to $1.8 \mathrm{~Hz}$ and $1.6 \mathrm{~Hz}$ to $1.8 \mathrm{~Hz}$, respectively. Other experiments have opposite phenomenon that crowd model frequency changes small with increasing $\beta$, and most of the obtained frequency is $2.0 \mathrm{~Hz}$. It is remarkable that each curve has a minimum point in the Figure 18, that meaning the simulated structural acceleration is close to the test result, and what is more, the corresponding crowd parameters combination may be available for reflecting the crowd model dynamic parameters when crowd on the TDG at this experimental condition. The flow chart of this optimization method is depicted in Figure 20. Utilizing this method, another five kinds of seismic wave experiments data are also analyzed. The details of statistic analysis of the results will be presented in Section 3.

\section{Results and discussion}

Based on the Algorithms in Figure 6 and Figure 20, with seventy-five experimental curves resulted in 1350 simulated combination values that are crowd model parameters. Each combination parameters: $f_{h}, \zeta_{h}, \gamma$ is the corresponding value that computed the min RMSAE. Analysis of the 918 parameter data sets when the structure was occupied by crowd seated, finding that all the predictive results indicate $\zeta_{h}$ is 0.5 , and the crowd model mass ratio $\gamma$ varies between 0.7 and 1.0. Therefore, the distributions of crowd model frequencies are shown in detail with 3D histogram (Figure 21). The abscissa axes are the parameter $\beta$ and crowd model frequency $f_{h}$ respectively, the vertical axis stands for the number of $f_{h}$. There are $634 f_{h}$ data that $\gamma$ is 0.7 , as is obviously shown in the upper left figure, these results from 174 data from Chi Chi (N-S) waves experiment; 120 data from Chi Chi (W-E) waves experiment; 119 data from El Centro (N-S) waves experiment; 130 data from El Centro (W-E) waves experiment; 46 points from Kobe $(\mathrm{N}-\mathrm{S})$ waves experiment and 45 points from Kobe (W-E) waves experiment respectively. And the distributions of these data reveal the crowd model frequencies only occur in the range between $1.5 \mathrm{~Hz}$ and $2.5 \mathrm{~Hz}$. In

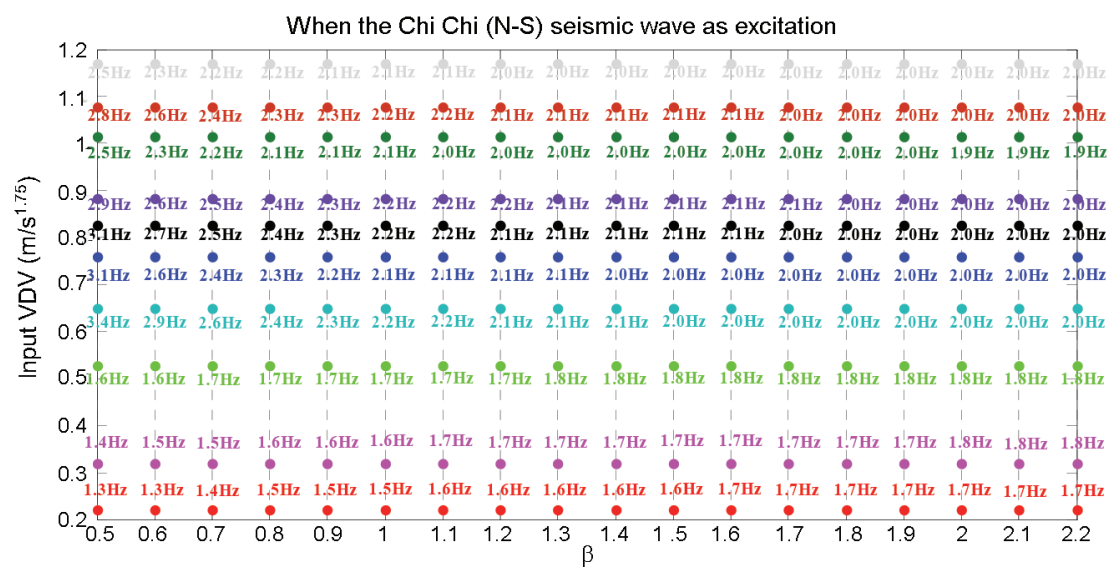

Figure 19. The crowd model frequency with eighteen $\beta$ and ten different amplitudes of Chi Chi (N-S) waves 


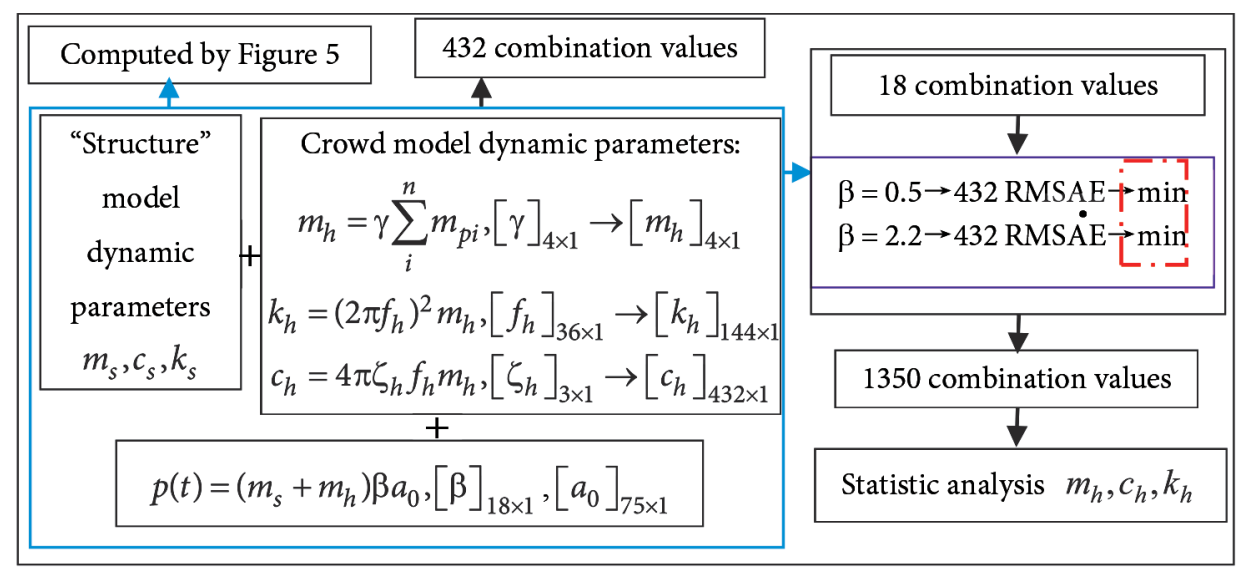

Figure 20. The flow chart of obtaining crowd dynamic parameters

the upper right figure there are 78 data including 23 data from Chi Chi (W-E); 12 data from El Centro (N-S); 9 data from El Centro (W-E); 16 data from Kobe (N-S) and 18 data from Kobe (W-E) wave experiment. And the model mass ratio $\gamma$ is 0.8 , the frequencies within the range $1.9 \mathrm{~Hz}$ to $2.5 \mathrm{~Hz}$. In the lower left figure, there are $56 f_{h}$ data are far from negligible, including 13 data from Chi Chi (W-E); 8 data from El Centro (N-S); 4 data from El Centro (W-E); 14 data from Kobe (N-S) and 17 data from Kobe (W-E) when the crowd model mass ratio $\gamma$ is 0.9 . Also in the lower right figure, 150 data including 7 data from Chi Chi (W-E); 6 data from El Centro (N-S); 6 data from El Centro (W-E); 68 data from Kobe (N-S) and 63 data from Kobe (W-E) when crowd model mass ratio $\gamma$ is 1.0. Both of the two figures show most of frequencies distribute at $1.8 \mathrm{~Hz}$ to $2.5 \mathrm{~Hz}$.
Similar to the previous analysis, the dynamic properties parameters data of the standing crowd model is presented in Figure 22. It is founding that all the data indicated the standing crowd model mass ratio $\gamma$ is 0.7 , and there are three crowd model damping ratio: $\zeta_{h}=0.3, \zeta_{h}=0.4$ and $\zeta_{h}=0.5$. The upper left histogram shows the distribution of 432 predictive crowd model frequency data. It can be seen that the frequencies are within the bound range from $0.5 \mathrm{~Hz}$ to $1.8 \mathrm{~Hz}$. In the upper right figure, there are 92 data when crowd model damping ratio $\zeta_{h}$ is 0.3 , and the distribution of frequency varies at $0.5 \mathrm{~Hz}$ to $1.4 \mathrm{~Hz}$. There are 232 data when $\zeta_{h}$ is 0.4 , and the distribution of frequency changes at $0.7 \mathrm{~Hz}$ to $1.7 \mathrm{~Hz}$ in the lower left figure. When $\zeta_{h}$ is 0.5 , there are 108 data distribute between $1.0 \mathrm{~Hz}$ and $1.8 \mathrm{~Hz}$, which is shown in the lower right figure.
The damping ratio $\zeta_{\mathrm{h}}$ is 0.5 and model mass ratio $\gamma$ is 0.7

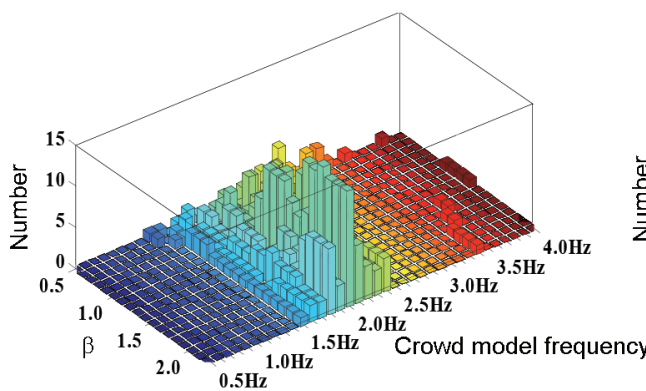

The damping ratio $\zeta_{h}$ is 0.5 and model mass ratio $\gamma$ is 0.9

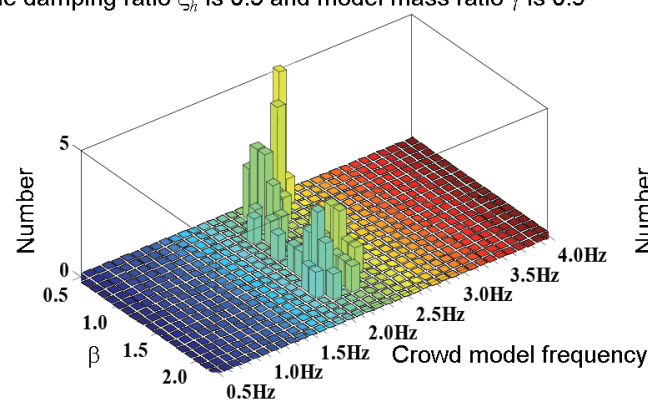

The damping ratio $\zeta_{h}$ is 0.5 and model mass ratio $\gamma$ is 0.8

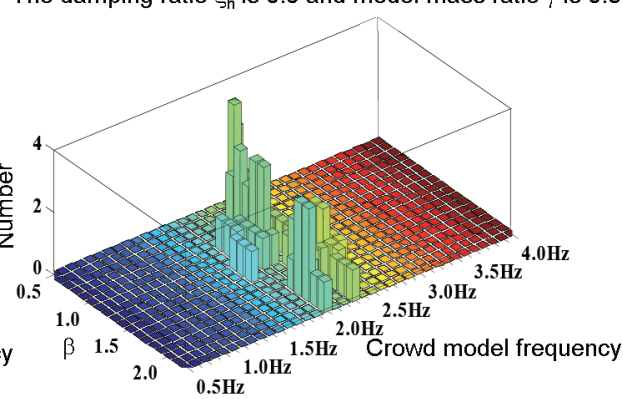

The damping ratio $\zeta_{h}$ is 0.5 and model mass ratio $\gamma$ is 1.0

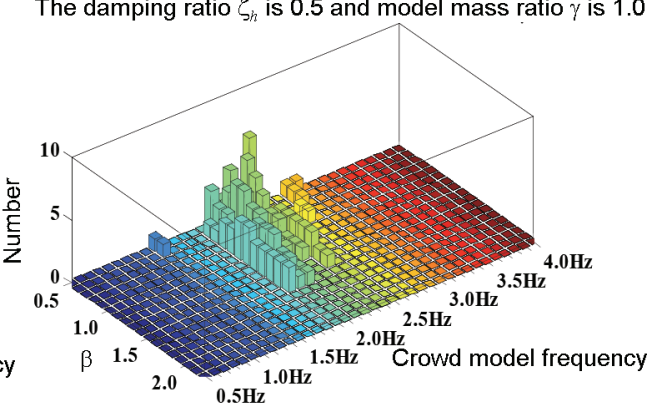

Figure 21 . The distribution of seated crowd model frequency $f_{h}$ against $\beta$ 

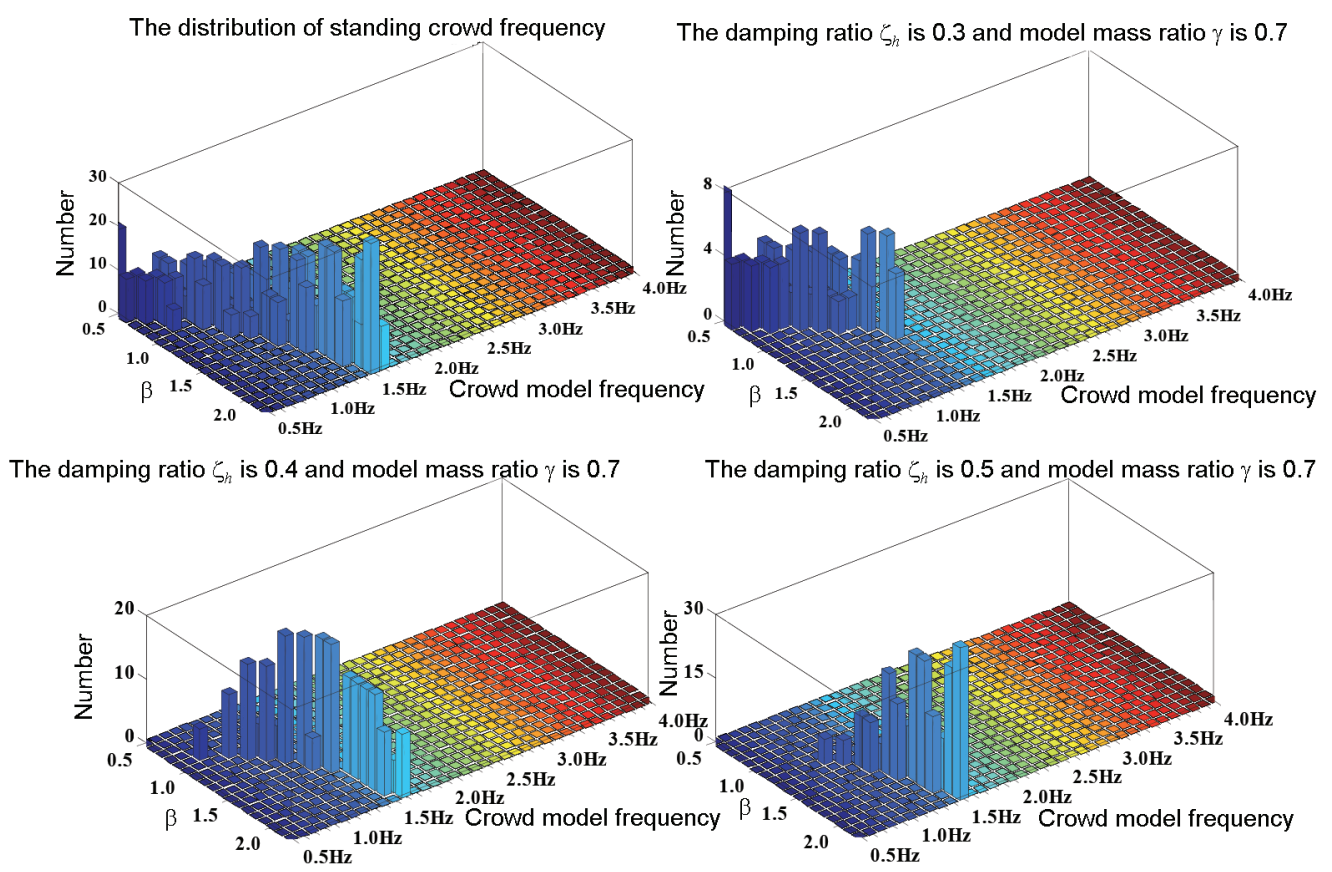

The damping ratio $\zeta_{h}$ is 0.5 and model mass ratio $\gamma$ is 0.7

Figure 22. The distribution of standing crowd model frequency $f_{h}$ against $\beta$

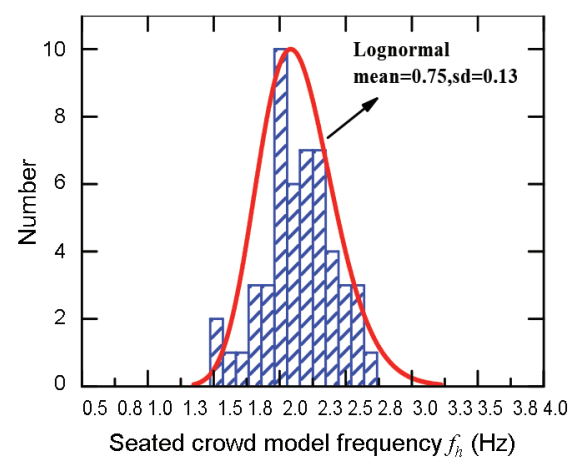

(a) The distribution of seated crowd model frequency

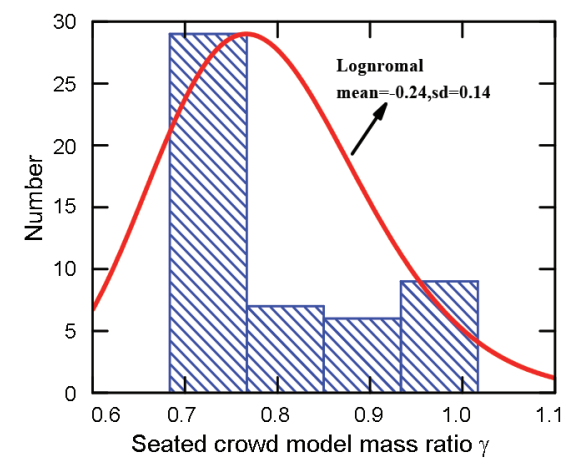

(b) The distribution of seated crowd model mass ratio

Figure 23. The predictive of seated crowd model frequency and mass ratio

As mentioned above, there will have a minimum value in the eighteen min RSMAEs for each experiment curve. So seventy five minimum values are obtained, and each of the minimum value can correspond a set of crowd model dynamic parameters $f_{h}, \zeta_{h}, \gamma$, which is considered to be the most likely dynamic response parameters of crowd who on the TDG at this experiment. It is important to realize that the crowd model damping ratio $\zeta_{h}$ is 0.5 for seated crowd, while crowd model frequencies $f_{h}$ and mass ratios $\gamma$ are varied. But for standing crowd, the crowd model mass ratio $\gamma 0.7$ is can clearly be identified, while crowd model frequencies $f_{h}$ and damping ratios $\zeta_{h}$ are varied. So the distributions of the two variable parameters are shown in Figure 23 and Figure 24, respectively. For predictive seated crowd model frequency, the range of it between $1.5 \mathrm{~Hz}$ and $2.7 \mathrm{~Hz}$, which satisfies the lognormal distribution, the highest number of frequency is $2.0 \mathrm{~Hz}$ (Figure 23(a)). Also the predictive seated crowd model mass ratio satisfies the lognormal distribution within the range 0.7 to 1.0 and the highest number of it is 0.7 that shown in Figure 23(b). While for predictive standing crowd model frequency, the range of it just only between $1.3 \mathrm{~Hz}$ to $1.6 \mathrm{~Hz}$, and it satisfies normal distribution, the highest number of it is $1.5 \mathrm{~Hz}$ (Figure 24(a)). Also the predictive standing crowd model damping ratio satisfies the normal distribution within the range 0.3 to 0.5 and the highest number of it is 0.4 which shown in Figure 24(b).

It is common to simulate passive human occupants as three models: additional mass only, additional mass and stiffness system, or considered human damped. When the structure is assumed as mass-stiffness-damper SDOF and the crowd also considered as SDOF, the human-structure 


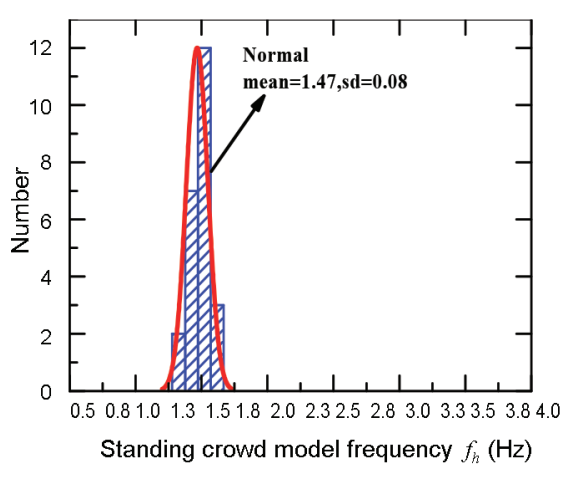

(a) The distribution of standing crowd model frequency

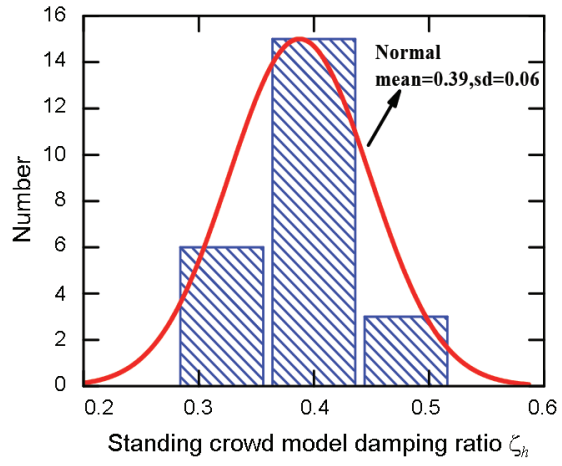

(b) The distribution of standing crowd model damping ratio

Figure 24. The predictive of standing crowd model frequency and damping ratio
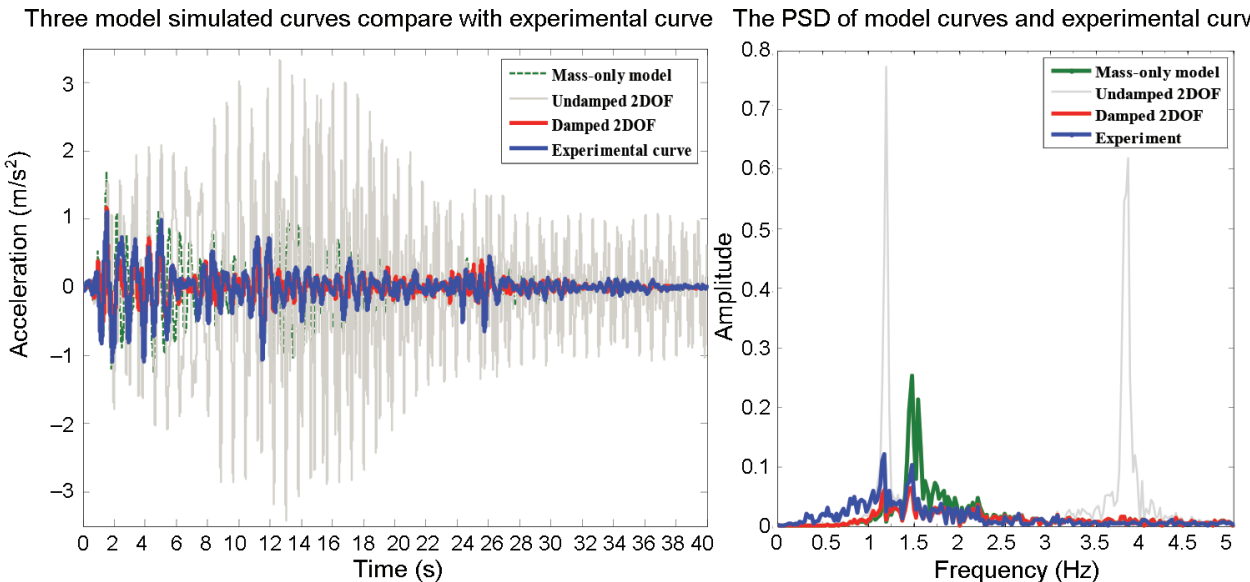

(a) Seated crowd model parameters simulated results
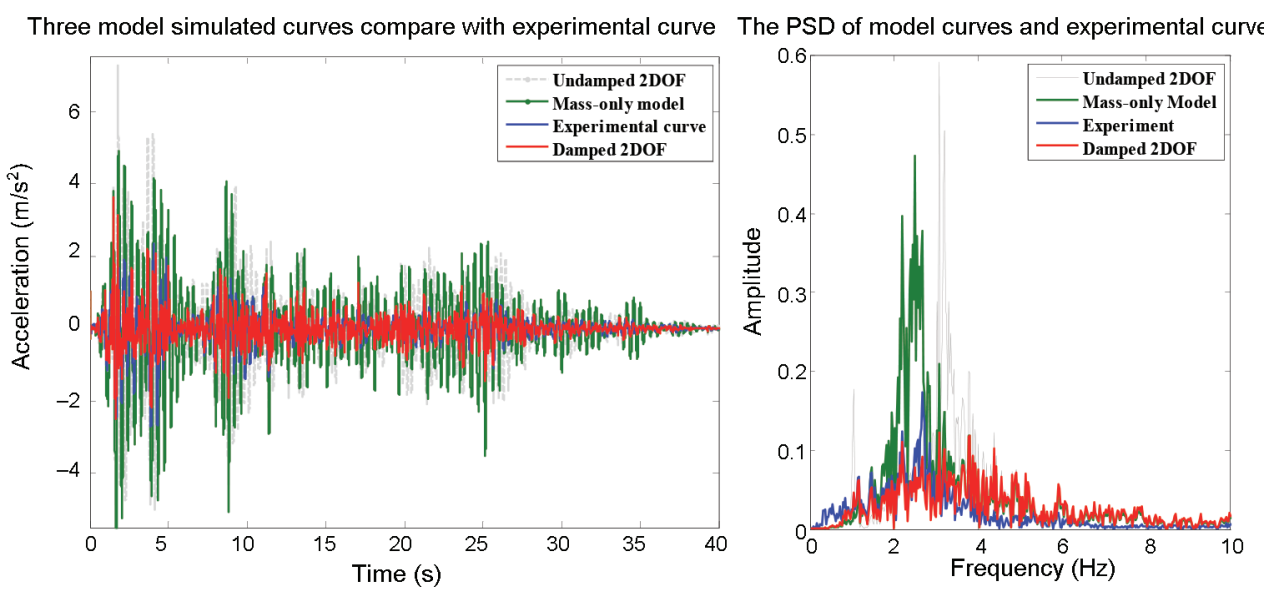

(b) Standıng crowd model parameters simulated results

Figure 25. Examples of acceleration of model curves and measured signals-time and frequency domain analysis

interaction model can be calculate three models, i.e. massonly model 2DOF, undamped 2DOF and damped 2DOF in civil engineering design. Therefore, the modeling strategy of predicting crowd dynamic properties presented in this paper is validated by a comparison of the simulated results of three models with the experimental results. Figure 25(a) illustrates the results that the seated crowd model dynamic parameters (when choose $f_{h}=1.8 \mathrm{~Hz}$, $\zeta_{h}=0.5$ and $\left.\gamma=0.8\right)$ of the three human-structure interaction models when the input force is one of the EI Centro (W-E) waves, and shows the analysis of time domain and frequency domain respectively. Figure 25(b) illustrates the results that the standing crowd model dynamic parameters (when choose $f_{h}=1.3 \mathrm{~Hz}, \zeta_{h}=0.4$ and $\gamma=0.7$ ) of the three human-structure interaction models when the input force is one of the EI Centro (N-S) waves. It is finding that 
what made the simulated look more like an experimental result (blue curve) is that the damped 2DOF system (red curve), on the contrary is undamped 2DOF (gray curve).

As described in Table 1, the range of these published literature given parameters are larger or reference values are higher than this paper predicted. That due to crowd occupied at a real structures are tested and the input excitations are different with these published literatures. Nevertheless, the parametric analysis performed in this paper has demonstrated the rationality of it being validated with experimental data. And as conclusively demonstrated in this paper, the human dynamic performance in this interaction model may possess a negligible variation due to different excitation. However, the fact is that what and how the crowd is doing, as well as different scales of structure or structure configurations may be considered the mode shapes influence, which can influence human bodies' dynamic properties. So the experimental results and model of this paper maybe required further verification and this need to test more big full-scale structures in the future.

Although all aspects of the problem have not been addressed at hand in this paper, the authors of this paper believe that the findings may be indicated the predicted crowd dynamic parameters are available in TDG design, and also have a ability to serve as a reference value that can be utilized in vibration safety and serviceability assessment of civil engineering assembly structures, to estimate realistically the vibration response on the occasions when crowd are seated or standing.

\section{Conclusions}

The paper explores the crowd of dynamic properties in the human-TDG interaction model that passive crowd occupied at TDG was oscillated by the shaking table. For TDG, prioritizing the seating system that crowd directly contact with the structure as a SDOF model is appropriate and the crowd model is assumed as mass-stiffness-damper SDOF system coupled with structural model is given to predict feasible crowd of dynamic properties. Based on the experiment data, a reasonable results are obtained and discussed: for seated crowds, the identified damping ratio is 0.5 , the model mass ratio ranges from 0.7 to 1.0 and the feasible natural frequency is around $2.0 \mathrm{~Hz}$; while for standing crowds the identified model mass is 0.7 , the damping ratio ranges from 0.3 to 0.5 and the feasible natural frequency is $1.5 \mathrm{~Hz}$; the predicted of natural frequency of seated crowds is larger than standing crowds, the contribution of damping for standing crowd is smaller than that of those seated for TDG, as with crowd mass.

\section{Nomenclature}

$A$ - the transition state matrix describing the dynamic of the system;

$B$ - the input matrix;

$D$ - the direct transmission matrix;
E - the output matrix;

$[\mathrm{C}]$ - the damping matrix of 2-d.o.f system $\left[\mathrm{N} \cdot \mathrm{s} / \mathrm{m}^{2}\right]$;

$[\mathrm{K}]$ - the stiffness matrix of 2-d.o.f system $\left[\mathrm{N} / \mathrm{m}^{2}\right]$;

$[\mathrm{M}]$ - the mass matrix of 2-d.o.f system [kg];

$\{F(t)\}$ - the force matrix of 2-d.o.f system [N];

$\{x(t)\}$ - the displacement matrix of 2-d.o.f system [m];

$a(t)$ - the digitized sample of the experimental acceleration $\left[\mathrm{m} / \mathrm{s}^{2}\right]$;

$a_{0}(t)$ - the acceleration of shaking table $\left[\mathrm{m} / \mathrm{s}^{2}\right]$;

$a_{V D V}$ - the acceleration vibration dose value $\left[\mathrm{m} / \mathrm{s}^{1.75}\right]$;

$a_{w}(t)$ - the frequency weighted acceleration $\left[\mathrm{m} / \mathrm{s}^{2}\right]$;

$a_{t, i}$ - the $i$ th data of experimental acceleration curve $\left[\mathrm{m} / \mathrm{s}^{2}\right]$;

$a_{s, i}-$ the $i$ th data of simulated acceleration curve $\left[\mathrm{m} / \mathrm{s}^{2}\right]$;

$c_{h}{ }^{-}$passive crowd model damping $\left[\mathrm{N} \cdot \mathrm{s} / \mathrm{m}^{2}\right]$;

$c_{s}$ - the damping of structure $\left[\mathrm{N} \cdot \mathrm{s} / \mathrm{m}^{2}\right]$;

$f-\quad$ the sampling frequency of test data [s];

$f_{\text {bag }}$ - the frequency of structure with sandbags $[\mathrm{Hz}]$;

$f_{h}$ - passive crowd model natural frequency [Hz];

$f_{S}-$ the natural frequency of structure $[\mathrm{Hz}]$;

$f_{S}^{\prime}-$ the natural frequency of structure with added mass $[\mathrm{Hz}]$;

$f_{u s}-$ the structural undamped frequency $[\mathrm{Hz}]$;

$f_{u s}{ }^{\prime}$ - the undamped natural frequency of structure with added mass [Hz];

$k_{h}{ }^{-}$passive crowd model stiffness $\left[\mathrm{N} / \mathrm{m}^{2}\right]$;

$k_{s}-$ the model stiffness of 1-d.o.f structure system $\left[\mathrm{N} / \mathrm{m}^{2}\right]$;

$k$ - the number person of crowd;

$\zeta_{s}^{\prime}-\quad$ the damping ration of structure with added mass $[\mathrm{Hz}]$;

$m_{b a g}$ - the weight of sandbags $[\mathrm{kg}]$;

$m_{b}$ - the added mass $[\mathrm{kg}]$;

$m_{h}-$ passive crowd model mass $[\mathrm{kg}]$;

$m_{p i}$ - the body weight of $i$ th person $[\mathrm{kg}]$;

$m_{s}-$ the model mass of 1-d.o.f structure system [kg];

$n-\quad$ the number of points in the signal;

$N$ - the number data of experimental or simulated curve;

$p(t)$ - the decoupled lateral force which was derived from the shaking table $[\mathrm{N}]$;

$x_{h}-$ the displacement of passive crowd model [m];

$x_{s}-$ the displacement of structure model $[\mathrm{m}]$;

$\ddot{x}_{i}$ - the $i$ th acceleration of structure $\left[\mathrm{m} / \mathrm{s}^{2}\right]$;

$\ddot{x}_{i+j}$ - the $(i+\mathrm{j})$ th acceleration of structure $\left[\mathrm{m} / \mathrm{s}^{2}\right]$;

$\Delta x_{i}-$ the ith integral interval point [s];

$t-\quad$ the vibration duration time [s];

$\Delta t_{i}-$ the $i$ th interval of time [s];

$W\left(f_{s}\right)$ - the frequency weight function;

$\beta-\quad$ the decoupled transfer coefficient;

$\gamma-\quad$ the passive crowd model mass ratio;

$\lambda$ - the max time range length [s];

$S_{i}-\quad$ the $i$ th integration point $[\mathrm{s}]$;

$\zeta_{h}-$ passive crowd model damping ration;

$\zeta_{s}-$ the damping ration of structure system;

$\Phi(x)$ - the unity-normalized mode shape of "structure". 


\section{References}

Agu, E.; Kasperski, M. 2011. Influence of the random dynamic parameters of the human body on the dynamic characteristics of the coupled system structure-crowd, Journal of Sound and Vibration 330(4): 431-444.

https://doi.org/10.1016/j.jsv.2010.06.029

BBC News. 2004. Religion show stand fall probed. Monday, 30 August [online], [cited 09 January 2018]. Available from Internet: http://news.bbc.co.uk

Bolton, A. 1992. Fatal mix caused stand fall, New Civil Engineer, 5-6.

Brito, V. L.; Pena, A. N.; Pimentel, R. L.; Brito, J. L. V. 2014. Modal tests and model updating for vibration analysis of temporary grandstand, Advances in Structural Engineering 17(5): 721-734. https://doi.org/10.1260/1369-4332.17.5.721

Brito, V. L.; Pimentel, R. L. 2009. Cases of collapse of demountable grandstands, Journal of Performance of Construction Facility 23(3): 151-159.

https://doi.org/10.1061/(ASCE)CF.1943-5509.0000006

Brito, V. L.; Pimentel, R. L. 2011. Finite element models for vibration analysis of temporary grandstands, in The $8^{\text {th }}$ International Conference on Structural Dynamics (EURODYN), 2011, Leuven, Belgium, 957-963.

Busca, G.; Cappellini, A.; Manzoni, S.; Tarabini, M.; Vanali, M. 2014. Quantification of changes in modal parameters due to the presence of passive people on a slender structure, Journal of Sound and Vibration 333(21): 5641-5652. https://doi.org/10.1016/j.jsv.2014.06.003

Cappellini, A.; Manzoni, S.; Tarabini, M.; Vanali, M.; Cigada, A. 2016. Evaluation of the dynamic behaviour of steel staircases damped by the presence of people, Engineering Structures 115: 165-178. https://doi.org/10.1016/j.engstruct.2016.02.028

Crick, D.; Gilbert, Y. G. 2008. Monitoring and analysis of a temporary grandstand. Structural Engineering Report No. 275. Department of Civil and Environmental Engineering, University of Alberta, Edmonton, Canada.

Dickie, J. F. 1983. Demountable grandstand, Structural Engineer 61(A3): 81-86.

Dickie, J. F.; Gibbs, S. 1991. Temporary seating assemblies, in: mobile and rapidly assembled structures, Topics in Engineering, Computational Mechanics Publications 8: 198.

Dickie, J. F.; Tomlinson, G. R. 1987. Static and dynamic considerations for demountable grandstands, in The International Conference on the Design and Construction of Non-Conventional Structure, 1987, London, UK,

Ellis, B. R.; Ji, T. 1997. Human-structure interaction in vertical vibration, Proceedings of Civil Engineers Structures and Buildings 122(1): 1-9. https://doi.org/10.1680/istbu.1997.29162

Fairley, T. E.; Griffin, M. J. 1990. The apparent mass of the seated human body in the fore-and-aft and lateral directions, Journal of Sound and Vibration 139(2): 299-306. https://doi.org/10.1016/0022-460X(90)90890-C

Foschi, R. O.; Gupta, A. 1987. Reliability of floors under impact vibration, Canadian Journal of Civil Engineering 14(5): 683689. https://doi.org/10.1139/187-098

Gibbs, S. 1990. Dynamic response of loosely jointed temporary grandstand seating: $\mathrm{PhD}$ thesis. University of Manchester, Manchester.

Greimann, L. F.; Klaiber, F. W. 1978. Dynamic forces induced by spectators, Journal of the Structural Division 104(ST2): 348-351.

Griffin, M. J. 1990. Handbook of human vibration. London: Academic Press.
Han, H. X.; Zhou, D.; Ji, T. 2017. Mechanical parameters of standing body and applications in human-structure interaction, International Journal of Applied Mechanics 9(2): 1750021. https://doi.org/10.1142/S1758825117500211

Harrison, R. E.; Yao, S.; Wright, J. R.; Reynolds, P. 2006. Humans bouncing on flexible structures-effect of structural properties, in The Conference Proceedings of the Society for Experimental Mechanics Series, IMAC-XXIV: Conference and Exposition on Structural Dynamic-Looking Forward: Technologies for IMAC, 2006, St. Louis, MI, United States.

Harrison, R. E.; Yao, S.; Wright, J. R.; Reynolds, P. 2008. Human jumping and bobbing forces on flexible structures: effect of structural properties, Journal of Engineering Mechanics 138(8): 663-675.

https://doi.org/10.1061/(ASCE)0733-9399(2008)134:8(663)

He, L.; Liu, C.; Wu, Z.; Yuan, J.. 2014. Parametric modeling and stability analysis of temporary grandstand, Applied Mechanics and Materials 578-579: 907-916. https://doi.org/10.4028/ www.scientific.net/AMM.578-579.907

Holmlund, P.; Lundstrom, R. 1998. Mechanical impedance of the human body in the horizontal direction, Journal of Sound and Vibration 215(4): 801-812. https://doi.org/10.1006/jsvi.1998.1593

HSL. 2011. Identification of safety good practice in the construction and deconstruction of temporary demountable structures. Health and Safety Laboratory, Buxton, United Kingdom.

Ibrahim, Z. 2006. The effects of crowds on dynamic characteristics of stadia structures: $\mathrm{PhD}$ thesis. The University of Sheffield, Sheffield, UK.

Institution of Structural Engineers (IStructE). 2007. Temporary demountable structures - guidance on design, procurement and use. $3^{\text {rd }}$ ed. London, United Kingdom.

Institution of Structural Engineers (IStructE). 2017. Temporary demountable structure - guidance on design, procurement and use. $4^{\text {th }}$ ed. London, United Kingdom.

ISO 2631 Mechanical vibration and shock-evaluation of human exposure to whole-body vibration. Part 1: General requirement. International Organization for Standardization (ISO), 1997.

ISO 2631 Mechanical vibration and shock-evaluation of human exposure to whole-body vibration. Part 1: Vibration in buildings $(1 \mathrm{~Hz}$ to $80 \mathrm{~Hz}$ ). International Organization for Standardization (ISO), 2003.

Jalil, N. A. A. 2016. Mathematical model of the apparent mass of the back of a seated person exposed to fore-and-aft wholebody vibration, in The ICSV 2016-23 ${ }^{\text {rd }}$ International Congress on Sound and Vibration: From Ancient to Modern Acoustics, 2016, Athens, Greece.

Jesus, C. Oliveira, T.; Brito, V. L.; Pimentel, R. L. 2014. Influence of seated spectators on the transverse modal properties of temporary grandstands, in Proceedings of the $9^{\text {th }}$ International Conference on Structural Dynamics, 2014, Portugal, Porto, 1013-1018.

Ji, T.; Ellis, B. R. 1997. Effective bracing systems for temporary grandstand, Structural Engineer 75(6): 95-100.

Ji, T.; Ellis, B. R.; Bell, A. J. 2003. Horizontal movements of frame structures induced by vertical loads, Proceedings of the Institution of Civil Engineers Structures \& Buildings 156(SB2): 141-150. https://doi.org/10.1680/stbu.2003.156.2.141

Joint Working Group (JWG). 2008. Joint Working Group Dynamic performance requirements: recommendations for management, design and assessment. IStructE/DCLG/DCMS.

Jones, C. A.; Reynolds, P.; Pavic, A. 2011. Vibration serviceability of stadia structures subjected to dynamic crowd loads: 
A literature review, Journal of Sound and Vibration 330(8):1531-1566. https://doi.org/10.1016/j.jsv.2010.10.032

LABC MG0220812 Temporary demountable structures, technical guidance note. Local Authority Building Control in England and Wales, United Kingdom, 2012.

Lasowicz, N.; Jankowski, R. 2013. Numerical analysis of a temporary steel grandstand, in The Shell Structures: Theory and Applications - Proceedings of the $10^{\text {th }}$ SSTA 2013 Conference, 2013, Gdansk, Poland, 3: 543-546.

Lasowicz, N.; Jankowski, R. 2015a. Application of polymer element in reduction of temporary steel grandstand vibrations, in The Advances in Mechanics: Theoretical, Computational and Interdisciplinary Isses-3 $3^{\text {rd }}$ Polish Congress of Mechanics, PCM 2015 and $21^{\text {st }}$ International Conference on Computer Methods in Mechanics, 2015, Gdansk, Poland, 331-334.

Lasowicz, N.; Jankowski, R. 2016b. Experimental and numerical study on polymer element used for reduction of temporary steel grandstand vibrations, in The Recent Progress in Steel and Composite Structures - Proceedings of the $13^{\text {th }}$ International Conference on Metal Structures, 2016, Zielona Gora, Poland, 215-222.

Lasowicz, N.; Jankowski, R. 2016a. The effectiveness of polymer damper in damage reduction of temporary steel grandstand, Key Engineering Materials 713: 171-174.

https://doi.org/10.4028/www.scientific.net/KEM.713.171

Lasowicz, N.; Kwiecie, A.; Jankowski, R. 2015b. Experimental study on the effectiveness of polymer damper in damage reduction of temporary steel grandstand, in The $11^{\text {th }}$ International Conference on Damage Assessment of Structures, 2015, Ghent, Belgium.

Lenzen, K. H. 1996. Vibration of steel joist-concrete slab floors, AISC Engineering Journal 3: 133-134.

Littler, J. D. 1996. Measuring the dynamic response of temporary grandstands, in Proceedings of Structural Dynamics (EURODYN 96), 1996, Florence, Italy.

Littler, J. D. 2002. Temporary demountable grandstands: dynamic response. Watford: Building Research Establishment.

Mansfield, N. J.; Lundstrom, R. 1999. The apparent mass of the human body exposed to non-orthogonal horizontal vibration, Journal of Biomechanics 32(12): 1269-1278.

https://doi.org/10.1016/S0021-9290(99)00135-9

Marinho, I. J. P.; Vaz, L. E.; Pimentel, R. L. 2006. Optimization of temporary grandstands through finite element analysis, in The $17^{\text {th }}$ International Congress of Mechanical Engineering, 2003, Sao Paulo, Brazil.

Matsumoto, Y.; Griffin, M. J. 2003. Mathematical model for the apparent masses of standing subjects exposed to vertical whole body vibration, Journal of Sound and Vibration 260(3): 431-451. https://doi.org/10.1016/S0022-460X(02)00941-0

Matsumoto, Y.; Griffin, M. J. 2011. The horizontal apparent mass of the standing human body, Journal of Sound and Vibration 330(13): 3284-3297. https://doi.org/10.1016/j.jsv.2011.01.030

MUTAmarq. 2013. Safe use and operation of temporary demountable fabric structures. London: Performance Textiles Association.

Nawayseh, N. 2015. Modelling of the vertical apparent mass at the seat surface and backrest, in The $29^{\text {th }}$ Annual European Simulation and Modelling Conference, 2015, Leicester, UK, 278-283.

Nhleko, S. 2011. Human-induced lateral excitation of public assembly structures: PhD thesis. University of Oxford, Oxford.

Nhleko, S.; Blakeborough, A.; Williams, M. S.; Whittle, J. 2010. Dynamic testing of bracing patterns of a demountable grandstand, in The Conference on Structural Engineering, Mechanics and Computation, 2010, Cape Town, South Africa, 89-92.

Pernica, G. 1983. Dynamic live loads at a rock concert, Canadian Journal of Civil Engineering 10(2): 185-191. https://doi.org/10.1139/183-034

Polensek, A. 1975. Damping capacity of nailed wood-joist floor, Wood Science 8(2): 141-151.

Rainer, J. H.; Pernica, G. 1981. Damping of a floor sample, in The Second Speciality Conference on Dynamic Response of Structures: Experimentation, Observation, Predication and Control, 1981, Atlanta, USA.

Reynolds, P.; Pavic, A.; Ibrahim, Z. 2004. Changes of modal properties of a stadium structure occupied by a crowd, in The $22^{\text {nd }}$ International Modal Analysis Conference (IMACXXII), 2004, Dearborn, Michigan, USA.

Sachse, R.; Pavic, A.; Reynolds, P. 2002. The influence of a group of humans on modal properties of a structure, in The Proceedings of the $4^{\text {th }}$ International Conference on Structural Dynamics, 2002, Munich, Germany.

Sachse, R.; Pavic, A.; Reynolds, P. 2003. Human-structure dynamic interaction in civil engineering dynamic: a literature review, Shock and Vibration Digest 35(1): 3-18. https://doi.org/10.1177/0583102403035001624

Sim, J. H. H. 2006. Human-structure interaction in cantilever stands: $\mathrm{PhD}$ thesis. The University of Oxford, Oxford.

Sim, J. H. H.; Blakeborough, A.; Williams, M. 2006. Modelling effects of passive crowds on grandstand vibration, Structures and Buildings 159(5): 261-272.

https://doi.org/10.1680/stbu.2006.159.5.261

The MATHWORKS. 2010. MATLAB $B^{R}$ software.

Tuan, C. Y.; Saul, W. E. 1985. Loads due to spectator movements, Journal of Structural Engineering 111(2): 418-434. https://doi.org/10.1061/(ASCE)0733-9445(1985)111:2(418)

Venuti, F.; Racic, V.; Corbetta, A. 2016. Modelling framework for dynamic interaction between multiple pedestrians and vertical vibrations of footbridges, Journal of Sound and Vibration 379: 245-263. https://doi.org/10.1016/j.jsv.2016.05.047

Wei, L.; Griffin, M. J. 1998. Mathematical model for the apparent masses of the seated human body exposed to vertical vibration, Journal of Sound and Vibration 212(5): 855-874. https://doi.org/10.1006/jsvi.1997.1473

Yao, S.; Wright, J. R.; Pavic, A.; Reynolds, P. 2006. Experimental study of human induced dynamic forces due to jumping on a perceptibly moving structure, Journal of Sound and Vibration 296(1-2): 150-165. https://doi.org/10.1016/j.jsv.2006.02.018

Yuan, J.; He, L.; Fan, F.; Liu, C.; Zhang, K. 2014. Dynamic modeling and vibration analysis of temporary grandstand due to crowd-jumping loads, in The Proceedings of the $9^{\text {th }}$ International Conference on Structural Dynamics, 2014, Portugal, Porto, 1051-1057.

Zhang, Z. F.; Hu, Z. Q.; Xu, Z. M.; He, Y. S.; Huang, S. R. 2016. A dynamic model of a seated human body based on dynamic response, Journal of Vibration and Shock 35(4): 104-109. 